\title{
Article \\ Structural Investigation into Magnetic Spin Orders of a Manganese Phosphatic Oxyhydroxide, $\mathrm{Mn}_{5}\left[\left(\mathrm{PO}_{4}\right)_{2}\left(\mathrm{PO}_{3}(\mathrm{OH})\right)_{2}\right](\mathrm{HOH})_{4}$
}

\author{
Sohyun Park ${ }^{1, *}$, Anna Hartl ${ }^{1,2}{ }^{\circ}$, Denis Sheptyakov ${ }^{2}\left({ }^{\circ}\right.$, Markus Hoelzel ${ }^{3}$ and Ana Arauzo ${ }^{4,5}$ \\ 1 Department of Geo- and Environmental Sciences, Section of Crystallography, \\ Ludwig-Maximilians-Universität München (LMU), Theresienstr. 41C, 80333 Munich, Germany; \\ anna.hartl@psi.ch \\ 2 Paul Scherrer Institute (PSI), Forschungsstrasse 111, 5232 Villigen, Switzerland; denis.cheptiakov@psi.ch \\ 3 Heinz Maier-Leibnitz Zentrum (MLZ), Technische Universität München, Lichtenbergstr. 1, \\ 85748 Garching, Germany; Markus.Hoelzel@frm2.tum.de \\ 4 Instituto de Nanociencia y Materiales de Aragón (INMA), Departamento de Física de la Materia Condensada, \\ CSIC-Universidad de Zaragoza, 50009 Zaragoza, Spain; aarauzo@unizar.es \\ 5 Physical Measurements Service, University of Zaragoza, 50009 Zaragoza, Spain \\ * Correspondence: sohyun.park@lmu.de; Tel.: +49-(0)89-2180-4333
}

check for updates

Citation: Park, S.; Hartl, A.; Sheptyakov, D.; Hoelzel, M.; Arauzo, A. Structural Investigation into Magnetic Spin Orders of a Manganese Phosphatic Oxyhydroxide, $\mathrm{Mn}_{5}\left[\left(\mathrm{PO}_{4}\right)_{2}\left(\mathrm{PO}_{3}(\mathrm{OH})\right)_{2}\right](\mathrm{HOH})_{4}$. Symmetry 2021, 13, 1688. https:// doi.org/10.3390/sym13091688

Academic Editor: P. Ulrich Biedermann

Received: 17 June 2021

Accepted: 16 August 2021

Published: 13 September 2021

Publisher's Note: MDPI stays neutral with regard to jurisdictional claims in published maps and institutional affiliations.

Copyright: (c) 2021 by the authors. Licensee MDPI, Basel, Switzerland. This article is an open access article distributed under the terms and conditions of the Creative Commons Attribution (CC BY) license (https:/ / creativecommons.org/licenses/by/ $4.0 /)$.

\begin{abstract}
The ferri- and antiferromagnetic structures of a hureaulite-type synthetic compound, $\mathrm{Mn}^{2+}{ }_{5}\left(\mathrm{PO}_{4}\right)_{2}\left(\mathrm{PO}_{3}(\mathrm{OH})\right)_{2}(\mathrm{HOH})_{4}$, were elucidated by high-resolution neutron powder diffraction in combination with magnetic susceptibility and heat capacity measurements. At $6.17 \mathrm{~K}$, the paramagnetic phase (space group: $C 2 / \mathrm{c}$ ) transforms to inherit a ferrimagnetic order (magnetic space group: $C 2^{\prime} / \mathrm{c}^{\prime}$ ), followed at $1.86 \mathrm{~K}$ by an incommensurately modulated antiferromagnetic order (magnetic superspace group: $\boldsymbol{P} 2_{1} / \mathrm{c} .1^{\prime}(\alpha 0 \gamma) 00$ s with the propagation vector $\boldsymbol{k}(0.523(2), 0,0.055(1)$ ). In the ferrimagnetic state, antiferromagnetic interactions are dominant for both intra and inter pentamers of $\mathrm{Mn}^{2+}(\mathrm{O}, \mathrm{HOH})_{6}$ octahedra. Differently aligned spin-canting sublattices seen in the ferrimagnetic models at 3.4, 4.5, and $6.1 \mathrm{~K}$ explain a weak ferromagnetism in the title compound. The observation of magnetic moments vigorously changing in a small temperature range of $6.1-1.5 \mathrm{~K}$ adumbrates a high complexity of interplaying structural and magnetic orders in this manganese phosphatic oxyhydroxide.
\end{abstract}

Keywords: magnetic structures; weak ferromagnetism; spin-canting; incommensurate antiferromagnetic order; phase transitions; hureaulite; phosphatic oxyhydroxides

\section{Introduction}

Transition metal phosphatic oxyhydroxides comprise an ample class of dense and porous framework structures occurring in nature [1,2]. Their variety and complexity are directly associated with the presence of $(\mathrm{OH})^{-}$and $(\mathrm{HOH})^{0}$ groups (non-zeolite water) responsible for various configurations of hydrogen bonds $(\mathrm{HBs})$. These $(\mathrm{OH})^{-}$and $(\mathrm{HOH})^{0}$ ligands along with $\mathrm{O}^{2-}$ form tetrahedra and octahedra, where $\mathrm{P}^{5+}$ and transition metal (TM) cations occupy those respective framework polyhedral centers. With respect to structure-related properties of this material class, fundamental studies of charge transport and proton tunneling over HB networks are application-relevant research topics attracting our interest [3-7]. At the same time, it is supposable to find new (multi)ferroic and magnetic structures depending on the type and arrangement of $3 d$ TM atoms in phosphatic oxyhydroxides. However, up to date, their magnetic structures are either completely unknown or have been poorly investigated. As a systematic approach to unveiling magnetic spin orders in this interesting material system, new antiferromagnetic (AFM) and ferrimagnetic (FM) structures of eosphorite- and rockbridgeite-type oxyhydroxides, respectively, could be determined in our recent studies using neutron diffraction techniques $[7,8]$. The current 
study aimed to determine magnetic structures of the pure manganese hureaulite-type solid solution $\mathrm{Mn}^{2+}{ }_{5}\left(\mathrm{PO}_{4}\right)_{2}\left(\left(\mathrm{PO}_{3}(\mathrm{OH})\right)_{2}(\mathrm{HOH})_{4}\right.$ (hereafter denoted as Mn-hureaulite).

Characteristically, the Mn-hureaulite structure contains pentamers of three edgesharing unique $\mathrm{Mn} 1 \mathrm{O}_{6}, \mathrm{Mn}_{2} \mathrm{O}_{4}(\mathrm{HOH})_{2}$, and $\mathrm{Mn} 3 \mathrm{O}_{5}(\mathrm{HOH})$ octahedra at Mn2-Mn3-Mn1$\mathrm{Mn} 3-\mathrm{Mn} 2$ atomic sites $[3,9,10]$. These pentamers are connected to each other via cornersharing $\mathrm{Mn}_{2} \mathrm{O}_{4}(\mathrm{HOH})_{2}$ and $\mathrm{Mn}_{3} \mathrm{O}_{5}(\mathrm{HOH})$ along with $\mathrm{PO}_{4}$ and $\mathrm{PO}_{3}(\mathrm{OH})$ tetrahedra to form zigzag-like interconnected pentamer slabs parallel to the $\boldsymbol{a}$ axis (Figure 1a). The resulting three-dimensional octahedral-tetrahedral oxyhydroxide framework exhibits onedimensional porous channels along the $c$ axis (Figure $1 b$ ). In this pore system, there are enantiomorphic semihelical chain couples of HBs over which protons are dynamically disordered $[3,4]$.

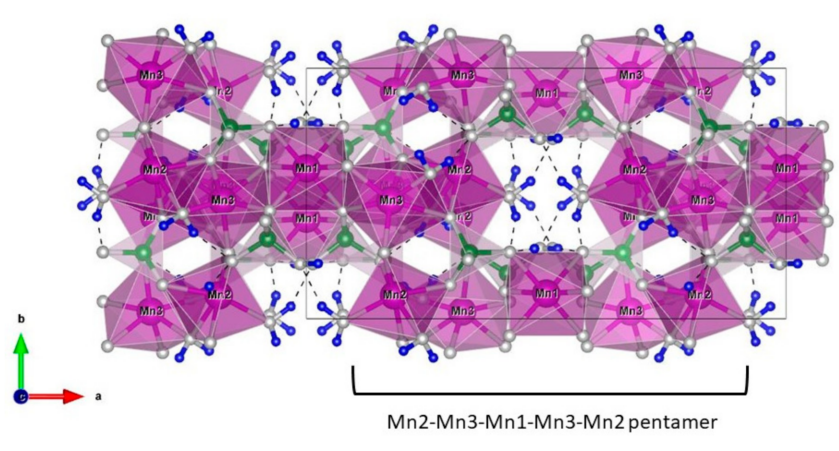

(a)

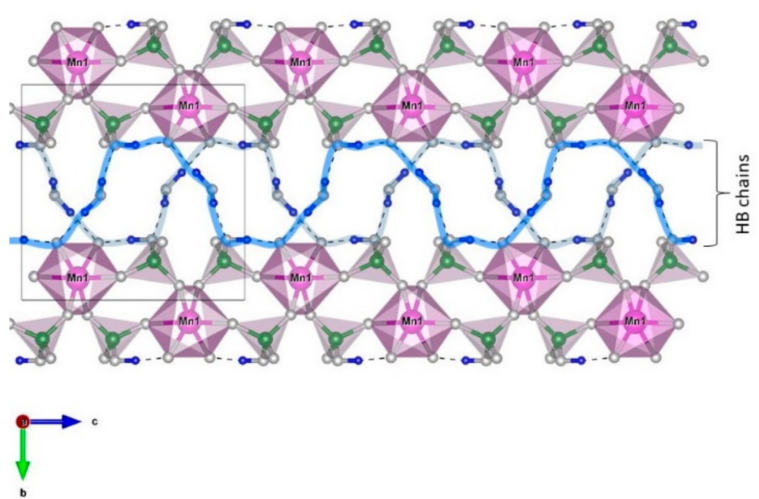

(b)

Figure 1. Representation of the atomic structure of Mn-hureaulite [3]. (a) The framework of Mn-hureaulite is built with pentamers of $\mathrm{Mn}(\mathrm{O}, \mathrm{HOH})_{6}$ which are connected to each other via $\mathrm{PO}_{4}$ and $\mathrm{PO}_{3}(\mathrm{OH})$ tetrahedra. $\mathrm{Mn}, \mathrm{P}, \mathrm{O}$, and $\mathrm{H}$ atoms are illustrated in pink, green, gray, and blue, respectively. (b) This mixed octahedral-tetrahedral framework exhibits one-dimensional channels running along the crystallographic $c$ axis. In each channel, there is one pair of enantiomorphic semihelical chains established by hydrogen bonds, where protons are dynamically disordered.

Previous Mössbauer spectroscopic studies on magnetic behavior of the hureaulite-type series $\mathrm{M}^{2+}{ }_{5}\left(\mathrm{PO}_{4}\right)_{2}\left(\left(\mathrm{PO}_{3}(\mathrm{OH})\right)_{2}(\mathrm{HOH})_{4}\right.$ with $\mathrm{M}=\mathrm{Mn}, \mathrm{Fe}$, and Co indicated antiferromagnetism in $\mathrm{Fe}$ - and $\mathrm{Co}$-rich solid solutions but a tendency to ferromagnetism in Mn-rich members [11-13]. In the current study, results from neutron powder diffraction studies of Mn-hureaulite explicate strong temperature-dependent FM spin arrangements below the Curie temperature $\left(T_{C}=6.17 \mathrm{~K}\right)$. In addition, we present its low-temperature magnetic phase, showing an incommensurately modulated AFM order stable below $1.86 \mathrm{~K}$.

\section{Materials and Methods}

\subsection{Sample Preparation and Phase Identification}

Details of hydrothermal synthesis conditions for a high yield of pure and highly crystalline Mn-hureaulite (protonated, i.e., H-form) can be found in our previous report [3]. The typical deuterated (D-form) sample preparation for neutron powder diffraction is as follows: the mixture of $0.1475 \mathrm{~g}$ of $\mathrm{SrCO}_{3}$ (Merck Technipur, Kenilworth, NJ, USA, $\geq 99.9 \%$ ), $0.2516 \mathrm{~g}$ of $\mathrm{MnCl}_{2}$ (Sigma Aldrich, St. Louis, MO, USA, $\geq 99 \%$ ), and $0.22517 \mathrm{~g}$ of $\mathrm{H}_{3} \mathrm{PO}_{4}$ (Merck, 85 wt.\%) was dissolved in $9 \mathrm{~mL}$ of $\mathrm{D}_{2} \mathrm{O}$ (VWR, Radnor, PA, USA, $\geq 99.90 \%$ ) and aged while stirring for one full day. This colloidal solution was charged in a $23 \mathrm{~mL}$ Teflon-lined stainless-steel autoclave (Parr Instruments) and allowed to react at $453 \mathrm{~K}$ in a convection oven (Nabertherm, Lilienthal, Germany, N30/45HA) for a cyclic heating of $2 \times 72 \mathrm{~h}$ with a short cooling period in between. The synthesis product was washed with heavy water and dried in a vacuum flask at room temperature. From a $10 \mathrm{~mL}$ starting solution, a maximum of about $0.1 \mathrm{~g}$ product could be yielded. To obtain several grams of samples for high-resolution neutron powder diffraction (HRNPD), the 
aforementioned synthesis task was repeated in series using several autoclaves. Every synthesis product from each autoclave was separately prepared for phase analyses using X-ray powder diffraction (XPD) on a Bragg-Brentano diffractometer (XRD3003, GE) with $\mathrm{MoK}_{\alpha 1}$ radiation (Ge(111)-monochromator). The phase purity and quality could be verified by comparison of XPD data collected with synthesis products from each autoclave to those of pure Mn-hureaulite samples reported in [3].

\subsection{Molar Heat Capacity and Magnetic Susceptibility Measurements}

Both heat capacity and magnetic susceptibility were measured on the $\mathrm{H}$-form of the title compound, i.e., $\mathrm{Mn}_{5}\left(\mathrm{PO}_{4}\right)_{2}\left(\left(\mathrm{PO}_{3}(\mathrm{OH})\right)_{2}(\mathrm{HOH})_{4}\right.$ (molecular weight $\left.=728.653 \mathrm{~g} / \mathrm{mol}\right)$.

The molar heat capacity $\left(C_{p}\right)$ was recorded with 1-2 mg of powdered sample using the semiadiabatic relaxation method on a Quantum Design Physical Properties Measurement System (PPMS), equipped with an ${ }^{3} \mathrm{He}$ refrigerator, in the temperature range of $0.35-300 \mathrm{~K}$. Samples were prepared as pressed powder pellets and fixed to the sample holder with Apiezon N grease. D.C. magnetic susceptibility was acquired at external fields (100 Oe) on another Quantum Design PPMS available for the temperature range of 2-300 K.

\subsection{High-Resolution Neutron Powder Diffraction (HRNPD)}

HRNPD was conducted with two batch samples of the D-form of Mn-hureaulite $\left(\mathrm{Mn}_{5}\left(\mathrm{PO}_{4}\right)_{2}\left(\mathrm{PO}_{3}(\mathrm{OD})\right)_{2}(\mathrm{DOD})_{4}\right)$. The data collection using $\lambda=2.5360(2) \AA$ was subsequently performed on a batch sample of $2.5 \mathrm{~g}$ at 6.5 and $3.4 \mathrm{~K}$ on the instrument SPODI at the neutron facility FRM II [14]. Further 6.5, 6.1, 4.5, 1.7, and 1.5 K HRNPD datasets were acquired using $\lambda=2.4500$ (1) $\AA$ on another batch sample of $1.5 \mathrm{~g}$ on the instrument HRPT at the neutron facility SINQ at PSI [15]. Rietveld refinements were carried out using the program package Jana2006 [16] with starting refinement parameters obtained from our recent studies [3]. Atomic and magnetic structure models refined were visualized using the program VESTA [17].

\section{Results and Discussion}

\subsection{Magnetic Phase Transitions}

D.C. magnetic susceptibility $\left(\chi_{D C}\right)$ of Mn-hureaulite revealed a nonlinear enhancement distinctively from about $6.2 \mathrm{~K}$ to near $2.2 \mathrm{~K}$ and then a fast drop down to its lowest measuring temperature $2 \mathrm{~K}$ (Figure 2a). This indicates two subsequent magnetic phase transitions; near $6.2 \mathrm{~K}$ (Curie temperature: $T_{C}$ ), Mn-hureaulite undergoes a magnetic phase transition from a paramagnetic (PM) to an FM and then to an AFM state near $2.0 \mathrm{~K}$ (denoted as $T_{1}$ ). Its reciprocal values $\left(1 / \chi_{\mathrm{DC}}\right.$ ) linearly decreasing from $50 \mathrm{~K}$ to $20 \mathrm{~K}$ confirm the PM state according to the Curie-Weiss law (Figure $2 b$ ). A negative Curie-Weiss temperature $\left(T_{\theta}\right)$ about $-33.5 \mathrm{~K}$, which was estimated by linear regression with $1 / \chi_{\mathrm{DC}}$ values between $20 \mathrm{~K}$ and $50 \mathrm{~K}$, indicates dominant antiferromagnetic interactions in Mnhureaulite. The inverse slope of $1 / \chi_{\mathrm{DC}}$ against $\mathrm{T}$ corresponds to a Curie constant $(C)$ value of $23.85 \mathrm{emu} \cdot \mathrm{K} \cdot \mathrm{mol}^{-1}$, allowing an estimation of the effective magnetic moment $\left(\mu_{\text {eff }}\right)$ value in Bohr magneton $\left(\mu_{B}\right)$. The resulting $\mu_{\text {eff }}$ value of $13.81 \mu_{B}$ is comparable with the value $13.53 \mu_{\mathrm{B}}$ reported in [12] but much larger than the magnetic moment $5.92 \mu_{\mathrm{B}}$ of a single isolated $\mathrm{Mn}^{2+}$ ion $\left(3 d^{5}\right.$, high-spin). Hence, a Mn pentamer may be regarded as the magnetic unit in Mn-hureaulite [12].

A $2 \%$ temperature rise needed for a good accuracy of the heat capacity in the applied relaxation technique gave rise to two peaks clearly resolved at $6.17 \mathrm{~K}$ and $1.86 \mathrm{~K}$ without compromising the peak height and shape. The molar heat capacity $C_{p}\left(\mathrm{~J} \cdot \mathrm{K}^{-1} \cdot \mathrm{mol}^{-1}\right)$ was normed by the gas constant $R=8.31446 \mathrm{~J} \cdot \mathrm{K}^{-1} \cdot \mathrm{mol}^{-1}$. In the resulting $C_{p} / R(\mathrm{~T})$ curve (Figure $3 \mathrm{a}$ ), these two peaks at $6.17 \mathrm{~K}$ and at $1.86 \mathrm{~K}$ could be unambiguously assigned to the respective temperatures $T_{C}$ and $T_{1}$ in accordance with $\chi_{D C}$ data. The relative error of $C_{p}$ showed a noticeable increase around $T_{1}$ (Figure $3 \mathrm{~b}$ ) when analyzing the error, which included the deviation from an exponential curve fit. On the other hand, there was a small $C_{p}$ anomaly at about $0.4 \mathrm{~K}$, showing a clear and reproducible change of slope at this 
temperature. However, the incomplete picture of the anomaly at $0.4 \mathrm{~K}$ due to experimental limitation below $0.35 \mathrm{~K}$ prevented a categorical assignment. Additional $C_{p}$ measurements through the main transitions upon heating and cooling showed no thermal hysteresis within experiment accuracy (Figure 3c,d).

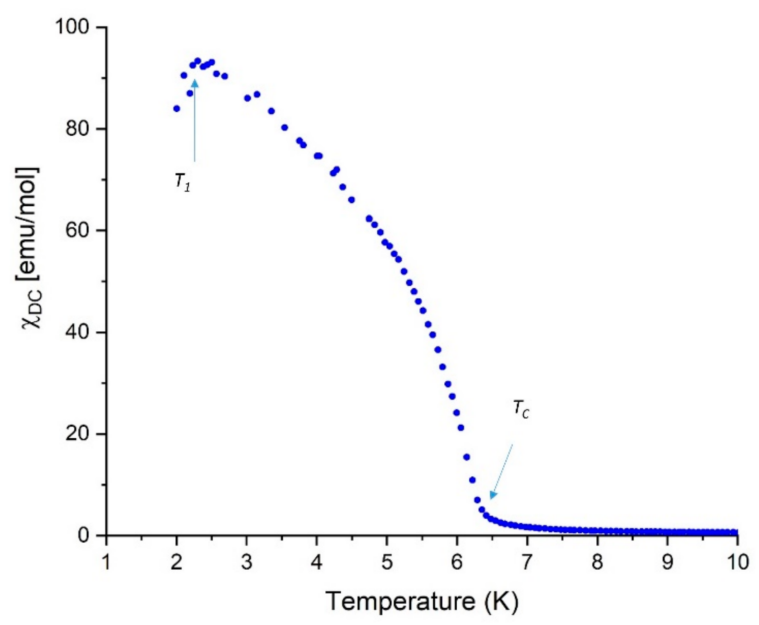

(a)

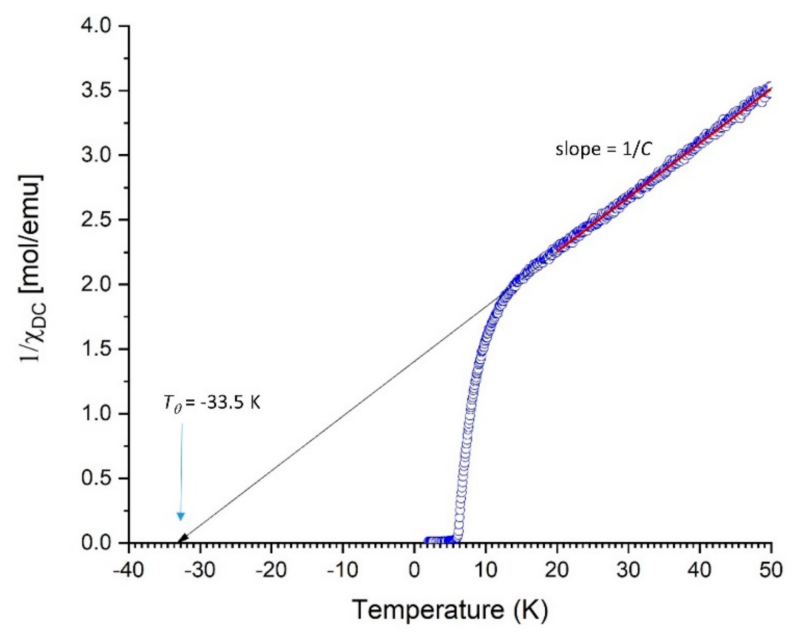

(b)

Figure 2. (a) D.C. magnetic susceptibility $\left(\chi_{D C}\right)$ of Mn-hureaulite shows two magnetic phase transitions at $T_{C}$ and $T_{1}$. (b) The inverse slope of $1 / \chi_{\mathrm{DC}}$ against temperature in a paramagnetic state range of $20-50 \mathrm{~K}$ gives rise to the Curie constant $C=23.85 \mathrm{emu} \cdot \mathrm{K} \cdot \mathrm{mol}^{-1}$ and the Curie-Weiss temperature $T_{\theta}=-33.5 \mathrm{~K}$.
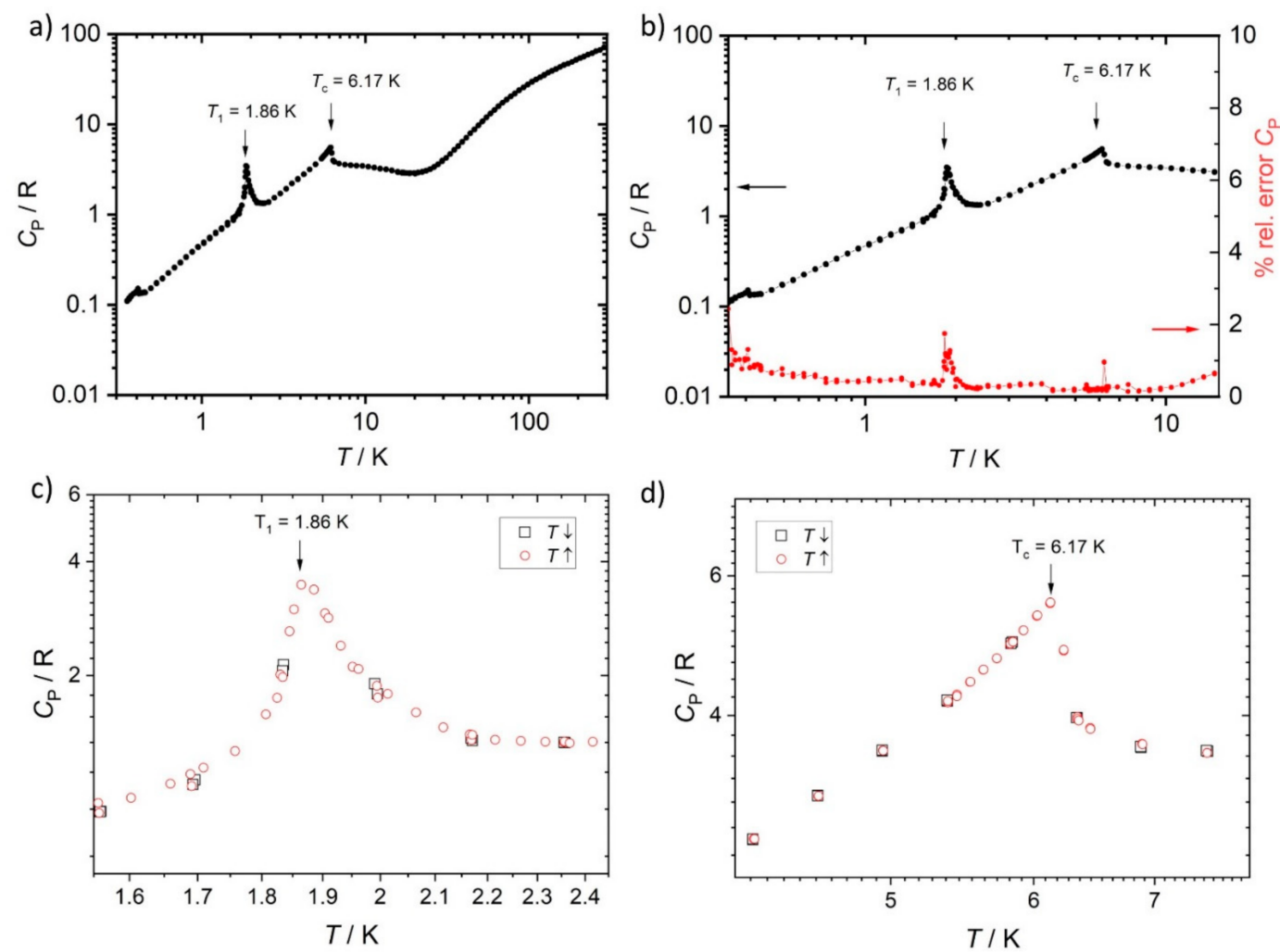

Figure 3. (a) $C_{p} / R(\mathrm{~T})$ shows two distinctive discontinuous points $T_{C}$ at 6.17 and $T_{1}$ at $1.86 \mathrm{~K}$. An additional small peak at about $0.4 \mathrm{~K}$ could denote a further magnetic phase transition at lower temperatures. An extremely broad bump centered around $10 \mathrm{~K}$ indicates a short-range magnetic order. (b) A noticeable increase around $T_{1}$ of the percentage of the relative error $C_{p}=\left(100 \times \operatorname{error}\left(C_{p}\right) / C_{p}\right)$ is indicative of a first-order transition at $T_{1}$. Additional $C_{p}$ measurements through $T_{1}(\mathbf{c})$ and $T_{C}(\mathbf{d})$ upon heating (circles in red) and cooling (squares in black) show no thermal hysteresis within experiment accuracy. 
The magnetic contribution $C_{m}$ to $C_{p}$ was estimated (Figure $4 \mathrm{a}$ ) after subtracting the lattice contribution $C_{L}$, without considering electron and nuclear contributions insignificant in the measuring temperature range. The lattice contribution term $C_{L} / R=0.01 \cdot \mathrm{T}^{1.75}$ was estimated from the linear temperature-dependent region of $C_{p}$ in $\log -\log$ scale between 30 and $70 \mathrm{~K}$. From integrating $C_{m}(\mathrm{~T})$ over $\mathrm{T}$, the magnetic heat $Q_{m}(\mathrm{~T})$ was obtained for $\mathrm{T}<20 \mathrm{~K}$ (Figure $4 \mathrm{~b})$. The integrated area of $Q_{m}(\mathrm{~T})$ around $T_{1}(1.5-2.2 \mathrm{~K})$ and $T_{C}(5.0-6.5 \mathrm{~K})$ gave rise to the respectively associated latent heat $Q_{L}$. The resulting $Q_{L}\left(T_{1}\right)=10 \mathrm{~J} \cdot \mathrm{mol}^{-1}$ and $Q_{L}\left(T_{C}\right)=57 \mathrm{~J} \cdot \mathrm{mol}^{-1}$ reflected the respective quantity of heat necessary for the AFM $\rightarrow$ FM and the FM $\rightarrow$ PM transition of Mn-hureaulite. The total magnetic entropy $S_{m}$ of an Mn pentamer can be calculated by $5 \times R \cdot \ln (2 S+1)=5 R \cdot \ln 6=74.45 \mathrm{~J} \cdot \mathrm{K}^{-1} \cdot \mathrm{mol}^{-1}$ with the spin angular moment $S=5 / 2$ for $\mathrm{Mn}^{2+}$. The entropy changes at $T_{1}$ and $T_{C}$ were obtained as $Q_{L}\left(T_{1}\right) / T_{1}=5.4 \mathrm{~J} \cdot \mathrm{K}^{-1} \cdot \mathrm{mol}^{-1}$ and $Q_{L}\left(T_{C}\right) / T_{C}=9.2 \mathrm{~J} \cdot \mathrm{K}^{-1} \cdot \mathrm{mol}^{-1}$. A small change in magnetic entropy $\left(\Delta S_{m}=3.4 \mathrm{~J} \cdot \mathrm{K}^{-1} \cdot \mathrm{mol}^{-1}\right)$ from the AFM to the FM state indicates that the AFM structure of Mn-hureaulite is only slightly higher ordered than the FM one. On the other hand, the total magnetic entropy $S_{m}(\mathrm{~T})$ evaluated for a Mn pentamer was much less than $5 R \cdot \ln (6)=8.96 R$ expected for complete ordering of localized $S=5 / 2$ spins, as shown by the small values $1.1 R$ and $3.67 R$ for $S_{m}\left(T_{1}\right)$ and $S_{m}\left(T_{C}\right)$, respectively (Figure $4 \mathrm{c}$ ). These point energetically stable magnetic spin arrangements, where a Mn pentamer acts as magnetic unit in this compound.

a)

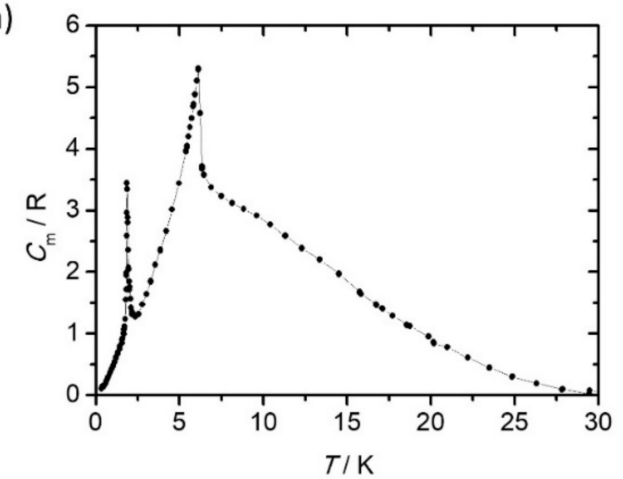

b)

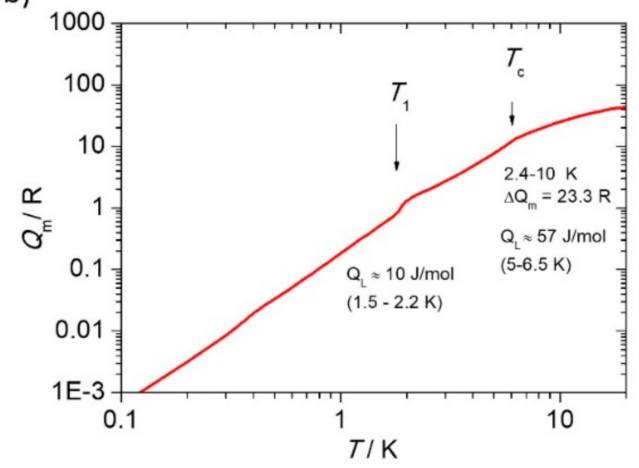

c)

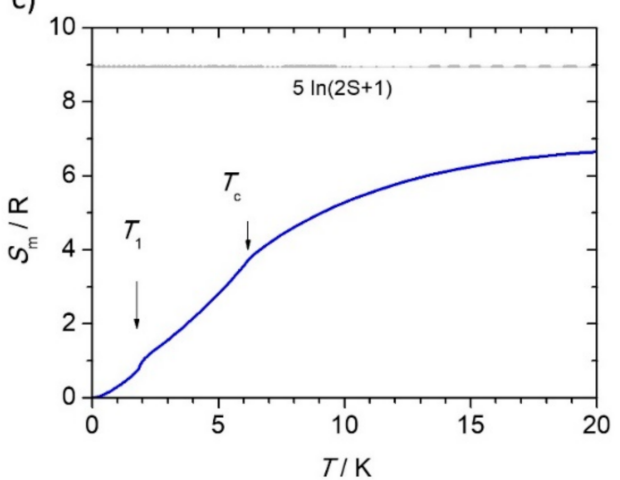

Figure 4. (a) Magnetic contribution of $C_{m} / R$ to $C_{p} / R$. (b) Magnetic heat $Q_{m}(T) / R$ with values evaluated for the latent heat $Q_{L}$ at $T_{1}$ and $T_{C}$ and for the magnetic heat change $\Delta Q_{m}$ at $T_{C}$. (c) Magnetic entropy $S_{m} / R$ evaluated for an Mn pentamer below $20 \mathrm{~K}$ is much less than $5 R \ln (2 S+1)$ expected for complete ordering of localized $S=5 / 2$ spins and shows no abrupt discontinuity.

Consequently, a high degree of long-range magnetic spin orders for both inter and intra pentamers was predicted below $T_{C}$ by heat capacity measurements. Interestingly, $C_{p} / R(\mathrm{~T})$ between $T_{C}$ and $20 \mathrm{~K}$ in Figure $4 \mathrm{a}$ exhibits an extremely broad bump centered around $10 \mathrm{~K}$. This observation resembles a broad magnetic heat capacity peak of ludlamite $\left(\mathrm{Fe}_{3}\left(\mathrm{PO}_{4}\right)_{2}(\mathrm{HOH})_{4}\right)$ at about $15 \mathrm{~K}$, which was explained by a linear-chain Ising model considering a short-range order in the AFM coupling between triads of Fe atoms [18]. 
Hence, there may be spin orientation disorder between pentamers in Mn-hureaulite before entering into the long-range FM order.

The temperature-induced evolution of magnetic spin orders in Mn-hureaulite was obvious when comparing its raw HRNPD datasets subsequently collected at 6.5, 6.1, 4.5, and $1.5 \mathrm{~K}$ with a constant wavelength of $2.45 \AA$ (Figure 5). A weak intensity for the reflection at $2 \theta=29.96^{\circ}$ was exclusively from the atomic order at $6.5 \mathrm{~K}$. The FM order contribution to this Bragg peak increased with decreasing temperatures between $T_{C}$ and $T_{1}$, as highlighted by the red arrow in Figure 5. This noticeable variation in a small temperature range from $6.1 \mathrm{~K}$ down to $4.5 \mathrm{~K}$ adumbrated vivid spin reorientations in the FM state. Below $T_{1}$ (e.g., at $1.5 \mathrm{~K})$, a high number of additional reflections of the AFM phase appeared.

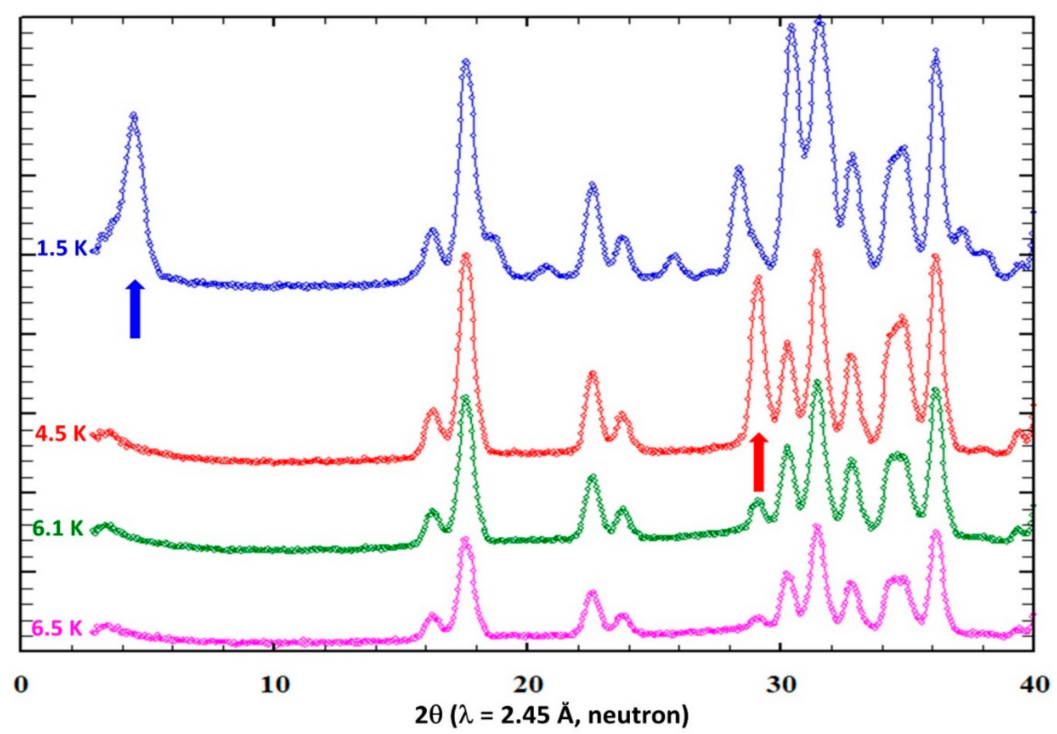

Figure 5. Comparison of raw HRNPD data of Mn-hureaulite collected in series at 6.5, 6.1, 4.5, and $1.5 \mathrm{~K}$ on the instrument HRPT at the neutron facility SINQ at PSI. The FM order contribution to the reflection 310 (red arrow) is strongly enhanced from $6.1 \mathrm{~K}$ to $4.5 \mathrm{~K}$, indicating vivid spin reorientations between $T_{C}$ and $T_{1}$. A high number of additional AFM reflections are seen in HRNPD at $1.5 \mathrm{~K}$, particularly the one near $4.5^{\circ}(2 \theta)$ highlighted by a blue arrow.

\subsection{PM and FM Structure Models Refined with HRNPD Data $(\lambda=2.536 \AA)$}

Rietveld analyses of $6.5 \mathrm{~K}$ and 3.4 K HRNPD datasets were performed with constraints on atomic displacement parameters (ADPs); isotropic ADPs for five independent deuterium (D) sites could be individually refined, whereas isotropic ADPs for Mn and O sites were only refined group-specifically. ADPs for P sites were fixed to a small value of $0.001 \AA^{2}$ as their values as free parameters became negative. In spite of the application of those constrained ADPs (Supplementary Table S1a), the calculated HRNPD pattern without magnetic contribution at $6.5 \mathrm{~K}$ in the space group $C 2 / \mathrm{c}$ was well matched to the observed one, as shown in graphical representation of the final cycle of refinements in Figure 6. This confirms the paramagnetic state at $6.5 \mathrm{~K}$ under zero external field. All experimental and refined cell parameters are given along with agreement factors in Table 1.

The refined atomic and profile parameters at $6.5 \mathrm{~K}$ were used as starting values in the following refinement with $3.4 \mathrm{~K}$ HRNPD data. In comparison to the $6.5 \mathrm{~K}$ HRNPD pattern, no extra Bragg peaks were detected in 3.4 K HRNPD data, along with a clear change in relative intensity distribution (Figure 7a). This difference was the most distinguishing feature in HRNPD patterns recoded above and below the Curie temperature $T_{C}$. In our case, as mentioned in the previous section, the reflection 310 at $2 \theta=29.96^{\circ}$ (marked as red arrows in Figures 5 and 6) was mostly sensitive to the occurrence of the FM phase of Mn-hureaulite, as its intensity dramatically increased at lowered temperatures below $T_{C}$. 


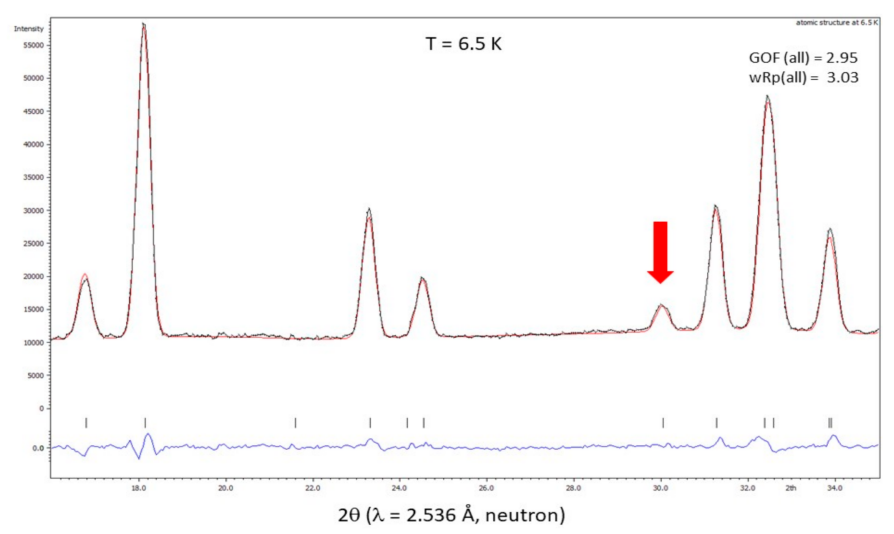

Figure 6. Graphical representation of results from Rietveld refinements with HRNPD data of deuterated Mn-hureaulite at $6.5 \mathrm{~K}$ with agreement factors. The calculated profile (red line) without magnetic contribution is well matched to the observed one (black line), as shown by their low difference profile (blue line). Short bars indicate Bragg refection positions expected for the atomic structure in the space group $C 2$ /c. The intensity of the 310 reflection (red arrow) would dramatically increase with the FM magnetic order (see the main text).

Table 1. Experimental and refinement parameters of neutron powder diffraction data of a synthetic Mn-hureaulite-type compound, $\mathrm{Mn}_{5}^{2+}\left[\left(\mathrm{PO}_{4}\right)_{2}\left(\mathrm{PO}_{3} \mathrm{OD}\right)_{2}\right](\mathrm{DOD})_{4}$.

\begin{tabular}{|c|c|c|c|c|c|c|c|}
\hline \multicolumn{2}{|c|}{ Temperature (K) } & 1.5 & 1.7 & 3.4 & 4.5 & 6.1 & $6.5 *$ \\
\hline \multicolumn{2}{|c|}{ Space group } & $C 2 / \mathrm{c}$ & $C 2 / \mathrm{c}$ & $C 2 / \mathrm{c}$ & $C 2 / \mathrm{c}$ & $C 2 / \mathrm{c}$ & $C 2 / \mathrm{c}$ \\
\hline \multicolumn{2}{|c|}{ Magnetic state } & AFM & AFM & FM & FM & FM & PM \\
\hline \multicolumn{2}{|c|}{ Magnetic space group } & $\begin{array}{l}P 2_{1} / c .1^{\prime} \\
(\alpha 0 \gamma) 00 s\end{array}$ & $\begin{array}{l}P 2_{1} / c .1^{\prime} \\
(\alpha 0 \gamma) 00 s\end{array}$ & $C 2^{\prime} / c^{\prime}$ & $C 2^{\prime} / c^{\prime}$ & $C 2^{\prime} / c^{\prime}$ & - \\
\hline \multirow{5}{*}{ Lattice metric } & a $(\AA)$ & $17.5715(5)$ & $17.6023(8)$ & $17.5717(2)$ & $17.5740(3)$ & $17.5986(6)$ & $\begin{array}{l}17.5748(4) \\
17.5717(2)\end{array}$ \\
\hline & b $(\AA)$ & $9.1185(3)$ & $9.1331(5)$ & $9.1179(1)$ & $9.1188(2)$ & $9.1315(3)$ & $\begin{array}{l}9.1186(2) \\
9.1181(1)\end{array}$ \\
\hline & $c(\AA)$ & $9.4931(3)$ & $9.5086(4)$ & $9.4936(1)$ & $9.4946(2)$ & $9.5068(3)$ & $\begin{array}{l}9.4944(2) \\
9.4937(1)\end{array}$ \\
\hline & $\beta\left(^{\circ}\right)$ & $96.391(1)$ & $96.391(2)$ & $96.408(1)$ & $96.393(1)$ & $96.391(1)$ & $\begin{array}{l}96.391(1) \\
96.409(1)\end{array}$ \\
\hline & $V\left(\AA^{3}\right)$ & $1511.6(1)$ & $1519.1(2)$ & $1511.5(1)$ & $1512.1(1)$ & $1518.2(1)$ & $\begin{array}{l}1512.1(1) \\
1511.6(1)\end{array}$ \\
\hline \multicolumn{2}{|c|}{ Modulation vector $k$} & $\begin{array}{c}(0.522(2), 0 \\
0.055(1))\end{array}$ & $\begin{array}{c}(0.545(2), 0 \\
-0.003(2))\end{array}$ & $(0,0,0)$ & $(0,0,0)$ & $(0,0,0)$ & - \\
\hline \multicolumn{2}{|c|}{ Density $\left(\mathrm{g} / \mathrm{cm}^{3}\right)$} & $3.2460(2)$ & $3.2299(3)$ & $3.2461(1)$ & $3.2449(1)$ & $3.2318(3)$ & $\begin{array}{l}3.2449(2) \\
3.2460(1)\end{array}$ \\
\hline \multicolumn{2}{|c|}{ Wavelength $(\AA)$} & 2.45 & 2.45 & 2.536 & 2.45 & 2.45 & $\begin{array}{c}2.45 \\
2.536\end{array}$ \\
\hline \multicolumn{2}{|c|}{ Data range $\left({ }^{\circ}(2 \theta)\right)$} & $2.4-163$ & $2.4-163$ & $0.95-155$ & $2.4-163$ & $2.4-163$ & $\begin{array}{c}2.4-163 \\
0.95-153\end{array}$ \\
\hline \multicolumn{2}{|c|}{$w \mathrm{R}$ (main reflections) } & 0.032 & 0.028 & 0.025 & 0.016 & 0.023 & $\begin{array}{l}0.030 \\
0.030\end{array}$ \\
\hline \multicolumn{2}{|c|}{$w \mathrm{R}$ (satellites) } & 0.033 & 0.030 & 0.032 & 0.019 & 0.024 & - \\
\hline \multicolumn{2}{|c|}{ GOF (profile) } & 4.79 & 2.86 & 2.43 & 2.53 & 1.95 & $\begin{array}{l}2.05 \\
2.95\end{array}$ \\
\hline
\end{tabular}

* Data acquisitions at $6.5 \mathrm{~K}$ were done with two different wavelengths of 2.45 and $2.536 \AA$ at HRPT (PSI) and SPODI (MLZ), respectively, with two different bulk samples of Mn-hureaulite. The parameters are given on the top $(2.45 \AA)$ and on the bottom $(2.536 \AA)$ of each row for $6.5 \mathrm{~K}$. 


$$
\begin{aligned}
& w \mathrm{R}=\sqrt{\frac{\sum_{i} w_{i}\left(y_{i}(o b s)-y_{i}(c a l)\right)^{2}}{\sum_{i} w_{i} y_{i}(o b s)^{2}}}, \\
& \mathrm{GOF}=\frac{\sqrt{\frac{\sum_{i} w_{i}\left(y_{i}(o b s)-y_{i}(c a l)\right)^{2}}{\sum_{i} w_{i} y_{i}(o b s)^{2}}}}{\sqrt{\frac{\sum_{i} w_{i} y_{i}(o b s)^{2}}{n-p}}},
\end{aligned}
$$

where $i$ runs over all points of the profile, $y_{i}(o b s)$ and $y_{i}$ (calc) are observed and calculated intensity, respectively, $n$ is the number of profile points, $p$ is the number of refined parameters, and $w_{i}=1 / \sigma^{2}\left(y_{i}(o b s)\right)$.

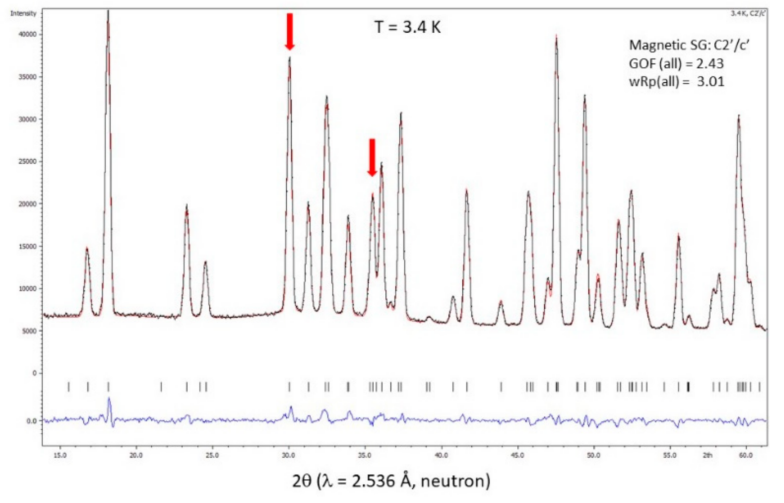

(a)

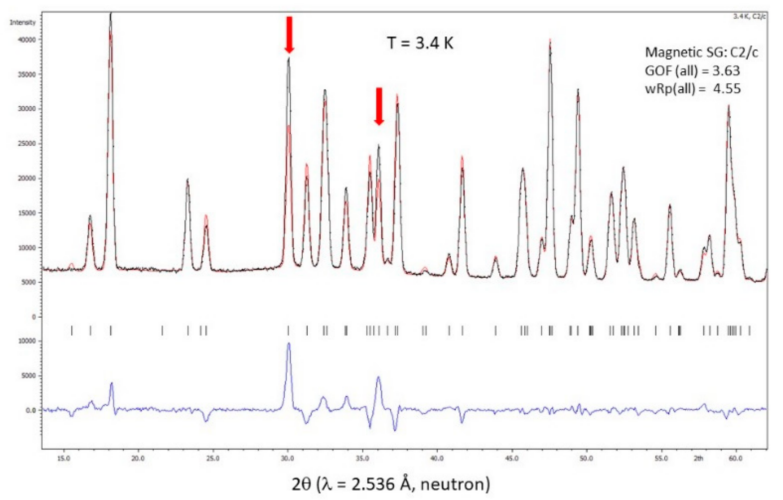

(b)

Figure 7. Graphical representation of results from Rietveld refinements with HRNPD data of deuterated Mn-hureaulite at $3.4 \mathrm{~K}$ with agreement factors. The calculated pattern (red line) for the FM magnetic space group $C 2^{\prime} / \mathrm{c}^{\prime}$ (a) matches the observed one (black line) much better than that for another FM magnetic space group C2/c (b). Short bars are Bragg reflection positions of the atomic structure with the space group $C 2 / \mathrm{c}$, overlapped with those in the respective FM space group symmetry $C 2^{\prime} / c^{\prime}(\mathbf{a})$ and $C 2 / c(b)$.

As given in Table 2, keeping the $(a \times b \times c)$ lattice for the magnetic and atomic unit cells (i.e., the propagation vector $k(0,0,0)$ ), there were four Shubnikov groups as direct magnetic subgroups of the space group $C 2 / c$, i.e., $C 2^{\prime} / c^{\prime}, C 2 / c, C 2 / c^{\prime}$, and $C 2^{\prime} / c$ [19]. Among them, $C 2 / \mathrm{c}^{\prime}$ and $C 2^{\prime} / \mathrm{c}$ were out of consideration because they gave rise to AFM orders with zero global magnetization (Table 2). Hence, with $3.4 \mathrm{~K}$, HRNPD data magnetic moments at three unique Mn sites (Table 3) were refined for two FM space groups $C 2^{\prime} / \mathrm{c}^{\prime}$ and $C 2 / c$. The former allowed for two global magnetization components $M_{x}$ and $M_{z}$ at all three $\mathrm{Mn}$ sites whereas the latter gave rise to one nonzero global magnetization component, $\mathrm{M}_{\mathrm{y}}$ only. Based on agreement factors of Rietveld refinements, $C 2^{\prime} / \mathrm{c}^{\prime}$ was identified as the correct magnetic space group for the FM phase at $3.4 \mathrm{~K}$. This can be clearly demonstrated by the difference profile flattened between observed and calculated HRNPD patterns of the model with $C 2^{\prime}$ / $c^{\prime}$ (Figure 7a). In contrary, Rietveld calculations for another FM model with $C 2 / \mathrm{c}$ resulted in large residuals in the difference pattern, particularly for both 310 and 021 reflections highlighted by arrows in Figure $7 \mathrm{~b}$. For an explicit comparison of $C 2^{\prime} / c^{\prime}$ to $C 2 / \mathrm{c}$, three magnetic sublattices resulted from Rietveld refinements with both FM space groups are illustrated in Figure 8. Atomic structure parameters refined with HRNPD data at $3.4 \mathrm{~K}$ are given in Table 3 (all atomic parameters obtained from HRNPD data analyses in this study are provided in Supplementary Table S1a-e). 
Table 2. Magnetic subgroups (Shubnikov groups [19]) of the space group $C 2 /$ are given with the magnetic moment $\mathbf{M}\left(\mathrm{M}_{\mathrm{x}}\right.$, $\mathrm{M}_{\mathrm{y}}, \mathrm{M}_{\mathrm{z}}$ ) allowed at the three Mn sites. Their global magnetization terms (given below the backslash) result in four different FM and AFM types. Mn1 is a special position while Mn2 and Mn3 are general positions (see Table 3).

\begin{tabular}{|c|c|c|c|c|}
\hline Magnetic Space Group & M at Mn1 & $\mathrm{M}$ at $\mathrm{Mn} 2$ & M at Mn3 & Magnetic Order \\
\hline$C 2^{\prime} / \mathrm{c}^{\prime}$ & $\left(\mathrm{M}_{\mathrm{x}}, 0, \mathrm{M}_{\mathrm{z}}\right) /\left(\mathrm{M}_{\mathrm{x}}, 0, \mathrm{M}_{\mathrm{z}}\right)$ & $\left(\mathrm{M}_{\mathrm{x}}, \mathrm{M}_{\mathrm{y}}, \mathrm{M}_{\mathrm{z}}\right) /\left(\mathrm{M}_{\mathrm{x}}, 0, \mathrm{M}_{\mathrm{z}}\right)$ & $\left(\mathrm{M}_{\mathrm{x}}, \mathrm{M}_{\mathrm{y}}, \mathrm{M}_{\mathrm{z}}\right) /\left(\mathrm{M}_{\mathrm{x}}, 0, \mathrm{M}_{\mathrm{z}}\right)$ & FM \\
\hline $\mathrm{C} 2 / \mathrm{c}$ & $\left(0, \mathrm{M}_{\mathrm{y}}, 0\right) /\left(0, \mathrm{M}_{\mathrm{y}}, 0\right)$ & $\left(\mathrm{M}_{\mathrm{x}}, \mathrm{M}_{\mathrm{y}}, \mathrm{M}_{\mathrm{z}}\right) /\left(0, \mathrm{M}_{\mathrm{y}}, 0\right)$ & $\left(\mathrm{M}_{\mathrm{x}}, \mathrm{M}_{\mathrm{y}}, \mathrm{M}_{\mathrm{z}}\right) /\left(0, \mathrm{M}_{\mathrm{y}}, 0\right)$ & FM \\
\hline$C 2 / c^{\prime}$ & $\left(0, \mathrm{M}_{\mathrm{y}}, 0\right) /(0,0,0)$ & $\left(\mathrm{M}_{\mathrm{x}}, \mathrm{M}_{\mathrm{y}}, \mathrm{M}_{\mathrm{z}}\right) /(0,0,0)$ & $\left(\mathrm{M}_{\mathrm{x}}, \mathrm{M}_{\mathrm{y}}, \mathrm{M}_{\mathrm{z}}\right) /(0,0,0)$ & AFM \\
\hline$C 2^{\prime} / \mathrm{c}$ & $(\mathrm{Mx}, 0, \mathrm{Mz}) /(0,0,0)$ & $(\mathrm{Mx}, \mathrm{My}, \mathrm{Mz}) /(0,0,0)$ & $(\mathrm{Mx}, \mathrm{My}, \mathrm{Mz}) /(0,0,0)$ & AFM \\
\hline
\end{tabular}

Table 3. Atomic structure parameters of Mn-hureaulite obtained from Rietveld refinements with HRNPD data at $3.4 \mathrm{~K}$ $\left(\mathbf{U}_{\text {iso }}\right.$ : isotropic atomic displacement parameter in $\left.\AA^{2}\right)$.

\begin{tabular}{|c|c|c|c|c|c|c|c|}
\hline \multirow{2}{*}{ Site } & \multirow{2}{*}{ Type } & \multicolumn{3}{|c|}{ Coordinates } & \multirow{2}{*}{$\mathrm{U}_{\text {iso }}$} & \multirow{2}{*}{ Occupancy } & \multirow{2}{*}{ Multiplicity } \\
\hline & & $x$ & $y$ & $z$ & & & \\
\hline Mn1 & Mn & 0 & $0.3995(9)$ & 0.25 & $0.001(1)$ & 1 & 4 \\
\hline Mn2 & Mn & $0.3173(3)$ & $0.4070(7)$ & $0.1862(5)$ & $0.001(1)$ & 1 & 8 \\
\hline Mn3 & $\mathrm{Mn}$ & $0.3247(3)$ & $0.0286(6)$ & $0.1344(6)$ & $0.001(1)$ & 1 & 8 \\
\hline P1 & $\mathrm{P}$ & $0.4192(3)$ & $0.1810(5)$ & 0.4078 (5) & 0.001 & 1 & 8 \\
\hline $\mathrm{P} 2$ & $\mathrm{P}$ & $0.1600(2)$ & $0.2366(5)$ & $0.1289(4)$ & 0.001 & 1 & 8 \\
\hline O1 & $\mathrm{O}$ & $0.5132(2)$ & $0.2808(5)$ & 0.0827 (5) & $0.0009(3)$ & 1 & 8 \\
\hline $\mathrm{O} 2$ & $\mathrm{O}$ & $0.4236(2)$ & $0.0684(4)$ & $0.2941(4)$ & $0.0009(3)$ & 1 & 8 \\
\hline $\mathrm{O} 3$ & $\mathrm{O}$ & $0.3450(2)$ & $0.2697(4)$ & $0.3705(3)$ & $0.0009(3)$ & 1 & 8 \\
\hline $\mathrm{O} 4$ & $\mathrm{O}$ & $0.0856(2)$ & $0.3900(4)$ & $0.4449(4)$ & $0.0009(3)$ & 1 & 8 \\
\hline O5 & $\mathrm{O}$ & $0.3377(2)$ & $0.2356(4)$ & $0.0324(4)$ & $0.0009(3)$ & 1 & 8 \\
\hline O6 & $\mathrm{O}$ & $0.2005(2)$ & 0.0957 (5) & $0.1727(4)$ & $0.0009(3)$ & 1 & 8 \\
\hline O7 & $\mathrm{O}$ & $0.2004(2)$ & $0.3647(4)$ & $0.2089(4)$ & $0.0009(3)$ & 1 & 8 \\
\hline O8 & $\mathrm{O}$ & $0.0760(2)$ & $0.2341(4)$ & $0.1568(4)$ & $0.0009(3)$ & 1 & 8 \\
\hline O9 & $\mathrm{O}$ & $0.2417(3)$ & $0.0801(5)$ & $0.4682(4)$ & $0.0009(3)$ & 1 & 8 \\
\hline $\mathrm{O} 10$ & $\mathrm{O}$ & $0.0767(3)$ & $0.0134(5)$ & $0.3529(5)$ & 0.0009 (3) & 1 & 8 \\
\hline D1 & $\mathrm{D}$ & $0.0244(2)$ & $0.2201(4)$ & $0.0093(5)$ & $0.024(1)$ & 1 & 8 \\
\hline D2 & $\mathrm{D}$ & $0.2647(2)$ & $0.1561(4)$ & $0.4145(4)$ & $0.015(1)$ & 1 & 8 \\
\hline D3 & $\mathrm{D}$ & $0.2025(2)$ & $0.1288(4)$ & $0.5232(4)$ & $0.010(1)$ & 1 & 8 \\
\hline $\mathrm{D} 4$ & $\mathrm{D}$ & $0.0635(2)$ & $0.0917(6)$ & $0.2830(4)$ & $0.022(1)$ & 1 & 8 \\
\hline D5 & $\mathrm{D}$ & $0.4675(2)$ & $0.4509(4)$ & $0.1406(4)$ & $0.020(1)$ & 1 & 8 \\
\hline
\end{tabular}

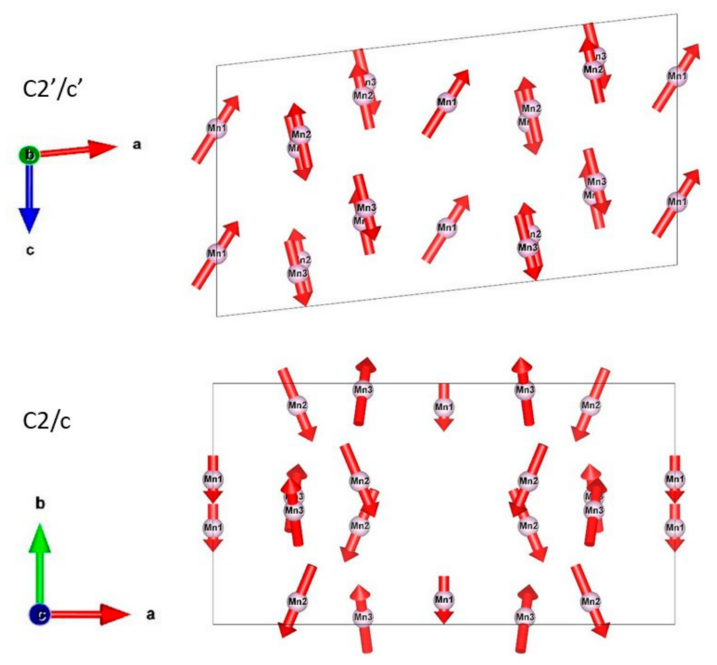

Figure 8. Magnetic spin structures refined with HRNPD data of Mn-hureaulite at $3.4 \mathrm{~K}$ for the two possible FM space groups $C 2^{\prime} / \mathrm{c}^{\prime}$ and $C 2 / \mathrm{c}$. 
In conclusion, at 3.4 K, Mn-hureaulite exhibits an FM order in $C 2^{\prime} / \mathrm{c}^{\prime}$, and the easy axis lies on the $(\boldsymbol{a}-\boldsymbol{c})$ plane (Table 4$)$. More interestingly, its magnetic moments vividly change between $a$ and $c$ by a small temperature range between $T_{C}$ and $T_{1}$, as described below.

Table 4. Magnetic moments in Bohr magnetons of Mn-hureaulite, refined in the FM space group $C 2^{\prime} / \mathrm{c}^{\prime}$ at $3.4,4.5$, and $6.1 \mathrm{~K}$.

\begin{tabular}{|c|c|c|c|c|}
\hline Atomic Site & Direction & $3.4 \mathrm{~K}$ & $4.5 \mathrm{~K}$ & $6.1 \mathrm{~K}$ \\
\hline \multirow{4}{*}{ Mn1 } & $a$ & $2.1(1)$ & $0.6(2)$ & $2.0(2)$ \\
\hline & $b$ & 0 & 0 & 0 \\
\hline & $c$ & $-3.1(1)$ & $-3.0(1)$ & $-1.8(4)$ \\
\hline & magnitude & $3.9(2)$ & $3.1(2)$ & $2.9(5)$ \\
\hline \multirow{4}{*}{ Mn2 } & $a$ & $-0.7(1)$ & $1.5(1)$ & $2.47(2)$ \\
\hline & $b$ & $0.1(2)$ & $0.1(2)$ & $0.3(4)$ \\
\hline & $c$ & $-3.32(6)$ & $-3.8(1)$ & $-1.4(2)$ \\
\hline & magnitude & $3.3(2)$ & $4.3(3)$ & $3.0(5)$ \\
\hline \multirow{4}{*}{ Mn3 } & $a$ & $0.9(1)$ & $2.9(1)$ & $3.0(2)$ \\
\hline & $b$ & $0.3(1)$ & $0.1(2)$ & $0.2(3)$ \\
\hline & $c$ & $3.37(6)$ & $2.48(8)$ & $0.9(2)$ \\
\hline & magnitude & $3.4(2)$ & $3.6(2)$ & $3.0(4)$ \\
\hline
\end{tabular}

3.3. Reorientation of Magnetic Moments in the FM State, Refined with $4.5 \mathrm{~K}$ and $6.1 \mathrm{~K} \mathrm{HRNPD}$ $\operatorname{Data}(\lambda=2.45 \AA)$

Results from Rietveld calculations for both $C 2^{\prime} / c^{\prime}$ and $C 2 / c$ models with HRNPD datasets collected at $4.5 \mathrm{~K}$ and $6.1 \mathrm{~K}$ could confirm that the FM phase retains the magnetic space group $C 2^{\prime} / \mathrm{c}^{\prime}$ from $T_{C}$ down to $T_{1}$ (graphical representations of results from Rietveld calculations are shown in Supplementary Figure S2). However, a strong temperaturedependent magnetic spin-canting reorientation was observed in the FM state. At 6.1 K, all three Mn sites exhibit large values for magnetic moments in the $a$ direction, but at $3.4 \mathrm{~K}$ in the $c$ direction (Table 4). Exemplarily, for a small temperature difference of $\Delta \mathrm{T}=1.6 \mathrm{~K}$, an explicit change of magnetic spin orientations is demonstrated in Figure 9a. The FM arrangement in the $(\boldsymbol{a}-\boldsymbol{b})$ plane is more obvious at $6.1 \mathrm{~K}$ than that at $4.5 \mathrm{~K}$ (Figure $9 \mathrm{~b}$ ). At lowered temperatures, the FM character parallel to the $a$ axis is abated due to the reorientation of magnetic moments toward the $c$ axis (especially at Mn1), while the AFM arrangement in the $(\boldsymbol{b}-\boldsymbol{c})$ plane becomes more obvious (Figure $9 \mathrm{~b})$. This strongly temperature-dependent reorientation of magnetic moments is graphically conflated in Figure 10.

Overall, the magnetic system of Mn-hureaulite exhibits a strong anisotropy with three differently aligned spin-canting Mn sublattices. Based on the geometry of inter and intra pentamers in the FM phase (Table 5, Figure 11), superexchange paths via Mn-OMn $>90^{\circ}$ might favor AFM couplings as dominant magnetic interactions for intra and inter pentamers [20]. Hence, spin-canting alignments varying across the Mn1-Mn2-Mn3 sublattices can be regarded as the main factor for a weak ferromagnetism detected by magnetic susceptibility measurements (Figure 2). Thus, our FM models between $T_{C}$ and $T_{1}$ could validate the tendency to ferromagnetism in Mn-rich hureaulite-type solid solutions, predicted by Mössbauer spectroscopic studies [11-13]. The refined magnetic moments at three unique Mn sites are given in Table 4. 


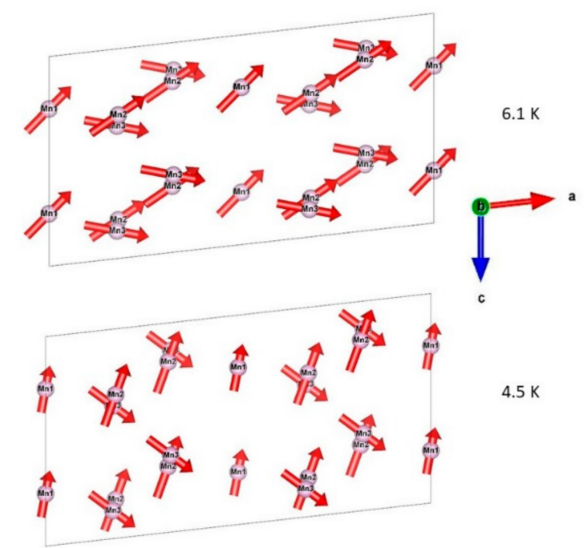

(a)

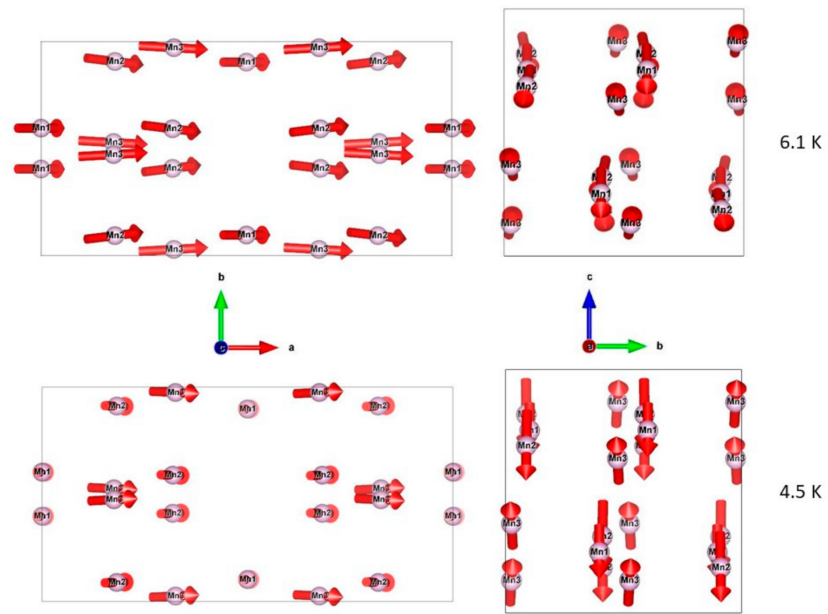

(b)

Figure 9. Changes in magnetic spin-canting sublattices of Mn-hureaulite between 4.1 and $6.5 \mathrm{~K}$ for the same FM symmetry $C 2^{\prime} / \mathrm{c}^{\prime}$ : (a) parallel to the easy axis plane $(\boldsymbol{a}-\boldsymbol{c}) ;(\mathbf{b})$ perpendicular to the easy axis plane.
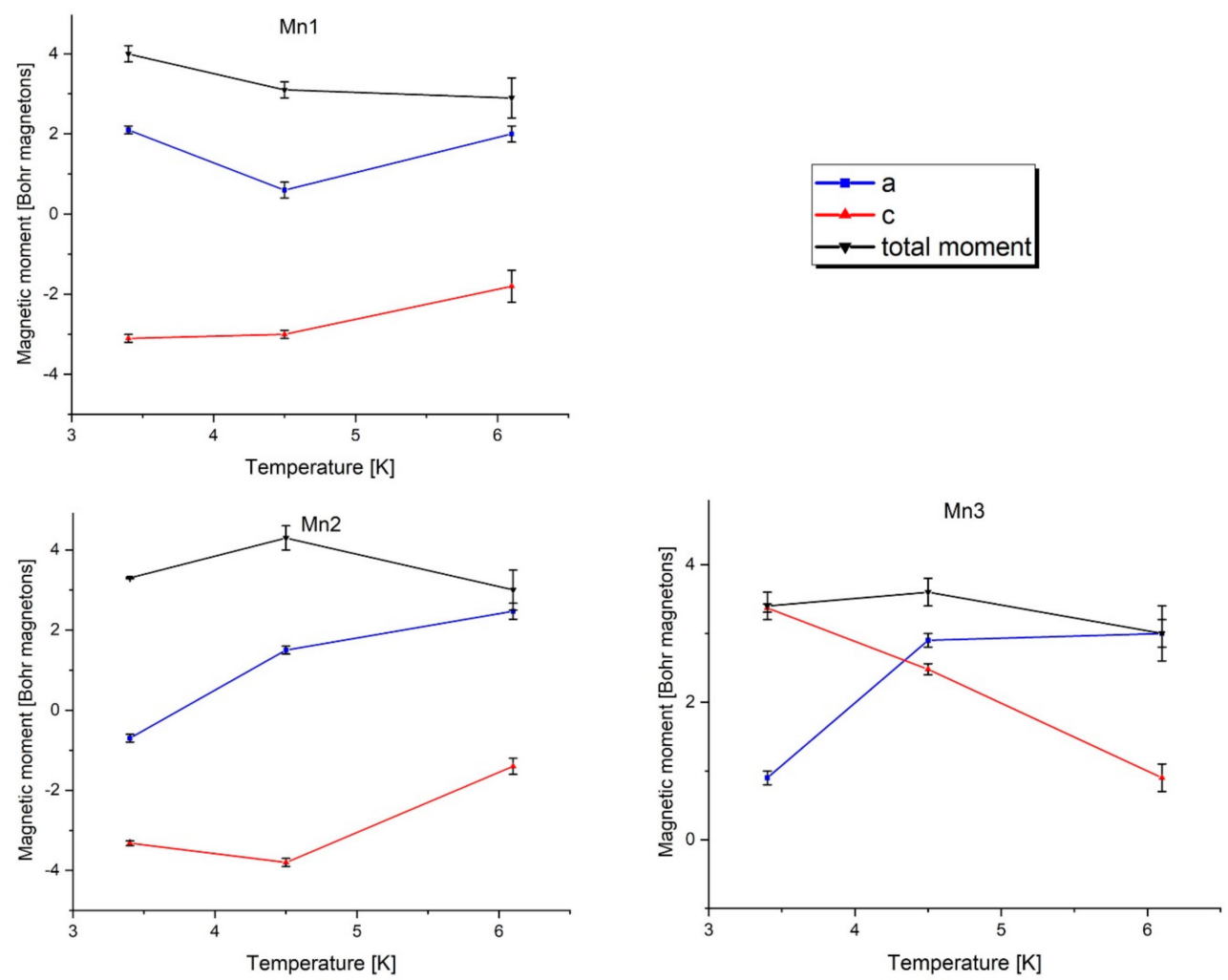

Figure 10. Change in magnetic moment components in $\boldsymbol{a}$ and $c$ directions and resulting total moments at three unique Mn sublattices in the FM phase temperature region. 
Table 5. Magnetic superexchange $\mathrm{Mn}-\mathrm{O}-\mathrm{Mn}$ angles in inter and intra pentamer of $\mathrm{Mn}(\mathrm{O}, \mathrm{HOH})_{6}$ in the ferrimagnetic structure of Mn-hureaulite at $3.4 \mathrm{~K}$.

\begin{tabular}{ccccc}
\hline Site 1 & Site 2 & Site 3 & Intra Pentamer Angle $\left(^{\circ}\right)$ & Inter Pentamer Angle $\left({ }^{\circ}\right)$ \\
\hline Mn2 & O6 & Mn3 & $95.058(1)$ & - \\
\hline Mn2 & O7 & Mn3 & $102.445(1)$ & - \\
\hline Mn3 & O2 & Mn1 & $102.311(1)$ & - \\
\hline Mn3 & O4 & Mn1 & $97.699(1)$ & - \\
\hline Mn2 & O9 & Mn3 & - & $110.583(1)$ \\
\hline
\end{tabular}

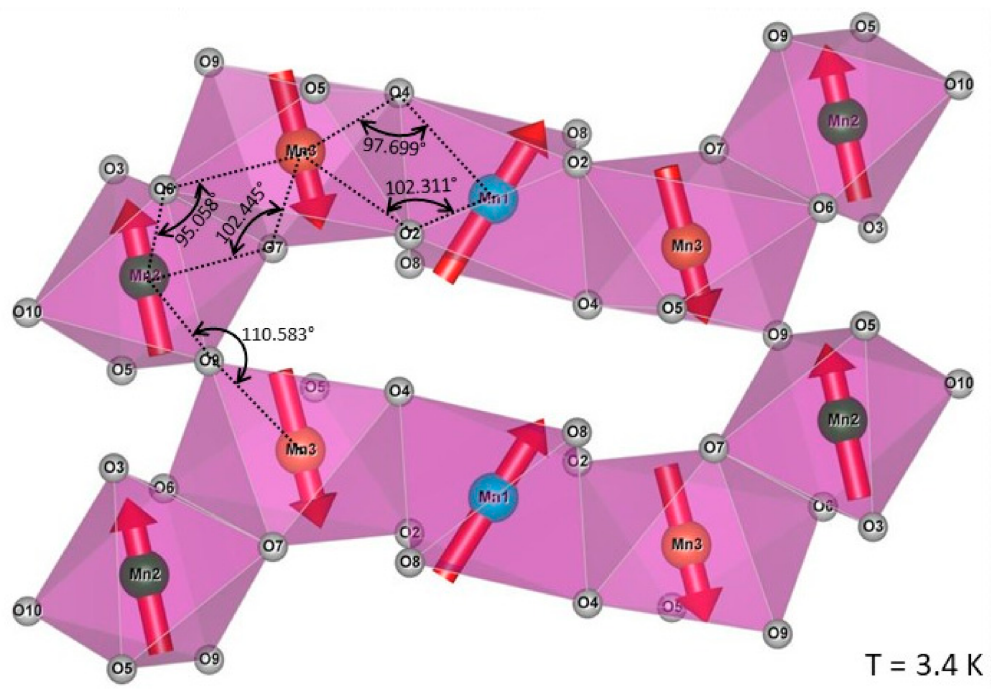

Figure 11. Spin-canting configurations indicate dominant AFM couplings for inter and intra pentamers in the FM phase of the title compound.

\subsection{The AFM Phase with Incommensurately Modulated Magnetic Spins Below $T_{1}$}

HRNPD data collected with $\lambda=2.45 \AA$ at 1.5 and $1.7 \mathrm{~K}$ exhibit additional Bragg reflections compared to those collected above $T_{1}$ (Figures 5 and 12). This features the presence of an AFM phase by the second phase transition. Rietveld analyses were done with both $1.5 \mathrm{~K}$ and $1.7 \mathrm{~K}$ HRNPD data, showing the same AFM structure, except for a distinctive decrease in the lattice metric from $1.7 \mathrm{~K}$ to $1.5 \mathrm{~K}$ (Table 1; Supplementary Figure S3). Hence, results from Rietveld analyses with 1.5 K HRNPD data are described below.

With the incommensurate modulation vector $\boldsymbol{k}(0.523(2), 0,0.055(1))$ determined at $1.5 \mathrm{~K}$ for an AFM order, its lattice might lose the $C$-centering to be primitive. Accordingly, there are four possible AFM orders in $\boldsymbol{P} 2_{1} /$ c. $1^{\prime}, P 2_{1} /$ n. $1^{\prime}, P 2 /$ c. $1^{\prime}$, and $P 2 / n .1^{\prime}$. Within the experimental resolution of our neutron diffraction data, we could exclude the presence of main reflections h0lm $(m=0)$ with $l=$ odd, as well as $0 k 0 m$ with $k=$ odd. Thus, only $P 2_{1} /$ c. $1^{\prime}$ was taken into account to select possible magnetic superspace groups (MSSG), i.e., $\boldsymbol{P} 2_{1} /$ c. $1^{\prime}(\alpha 0 \gamma) 00$ s and $\boldsymbol{P 2} 2_{1} /$ c. $1^{\prime}(\alpha 0 \gamma) 0 s s$. Note that $s$ in these one-line magnetic superspace group symbols [21] stands for a translation of $\frac{1}{2}$ in the fourth symmetry operator $x_{4}$ by time inversion $1^{\prime}$ involved in the operation (Table 6) [22]. Results from Rietveld calculations suggested the magnetic structure model in $P 2_{1} / \mathrm{c} .1^{\prime}(\alpha 0 \gamma) 00$ s with the weighted residual value of magnetic satellites $w R_{p}(\mathrm{mag})=0.033$ (Figure 12) rather than $P 2_{1} / \mathrm{c} .1^{\prime}(\alpha 0 \gamma) 0$ ss with $\mathrm{wR}_{\mathrm{p}}(\mathrm{mag})=0.043$. However, the current model in $\boldsymbol{P} 2_{1} / \mathrm{c} .1^{\prime}(\alpha 0 \gamma) 00$ s (Figure 13) was based on incommensurate modulations of magnetic moments refined without consideration of possible modulations in atomic positions and displacements below $T_{1}$. The difference pattern with the refined AFM model was relatively rough in comparison to those for the FM phase. Hence, it is necessary to improve the current AFM model. 


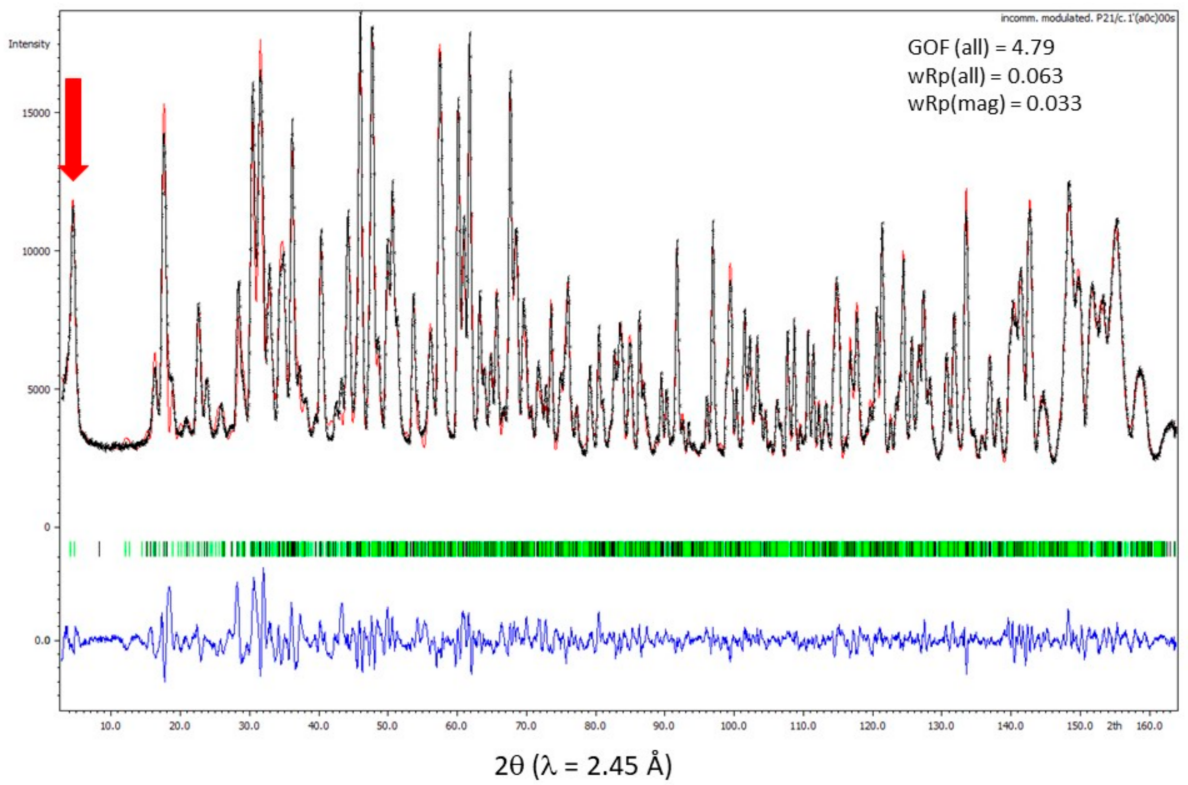

Figure 12. Graphical representation of results from Rietveld refinements with HRNPD data of deuterated Mn-hureaulite at $1.5 \mathrm{~K}$ with agreement factors according to the MSSG $\boldsymbol{P} 2_{1} / \mathrm{c} .1^{\prime}(\alpha 0 \gamma) 00$ s with $k(0.523(2), 0,0.055(1))$. Short bars in black and in green indicate Bragg reflection positions expected from the atomic arrangement and the magnetic spin order, respectively. There are a large number of additional reflections observed below $T_{1}$, comparing to HRNPD data of the FM phase (Figure $7 \mathrm{a}$ ), e.g., strong satellite peaks below $5^{\circ}(2 \theta)$ highlighted with a thick arrow.

Table 6. Representative operations of the MSSG P $2_{1} /$ c. $1^{\prime}(\alpha 0 \gamma) 00 s$. The generalized Seitz notation and symmetry operators used in JANA2006 [16] are listed with the label $m$ (no time inversion) and $-m$ (time inversion) involved in the symmetry operation.

\begin{tabular}{|c|c|c|c|c|c|}
\hline \multicolumn{6}{|c|}{$\boldsymbol{P} 2_{1} / \mathrm{c} .1^{\prime}(\alpha 0 \gamma) 00 \mathrm{~s}$} \\
\hline 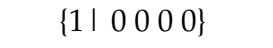 & $x_{1}$ & $x_{2}$ & $x_{3}$ & $x_{4}$ & $m$ \\
\hline$\left\{2_{1(0, y, 1 / 4)} \mid \begin{array}{lllll}0 & 0 & 0 & 0\end{array}\right\}$ & $-x_{1}$ & $x_{2}+1 / 2$ & $-x_{3}+1 / 2$ & $-x_{4}$ & $m$ \\
\hline$\left\{\begin{array}{llllll}-1 & \mid & 0 & 0 & 0 & 0\end{array}\right\}$ & $-x_{1}$ & $-x_{2}$ & $-x_{3}$ & $-x_{4}$ & $m$ \\
\hline$\left\{c_{(x, 1 / 4, z)} \mid \begin{array}{lllllll}0 & 0 & 0 & 0\end{array}\right\}$ & $x_{1}$ & $-x_{2}+1 / 2$ & $x_{3}+1 / 2$ & $x_{4}$ & $m$ \\
\hline$\left\{1^{\prime} \mid \begin{array}{lllll}0 & 0 & 0 & 0 & 0\end{array}\right\}$ & $x_{1}$ & $x_{2}$ & $x_{3}$ & $x_{4}+1 / 2$ & $-m$ \\
\hline
\end{tabular}

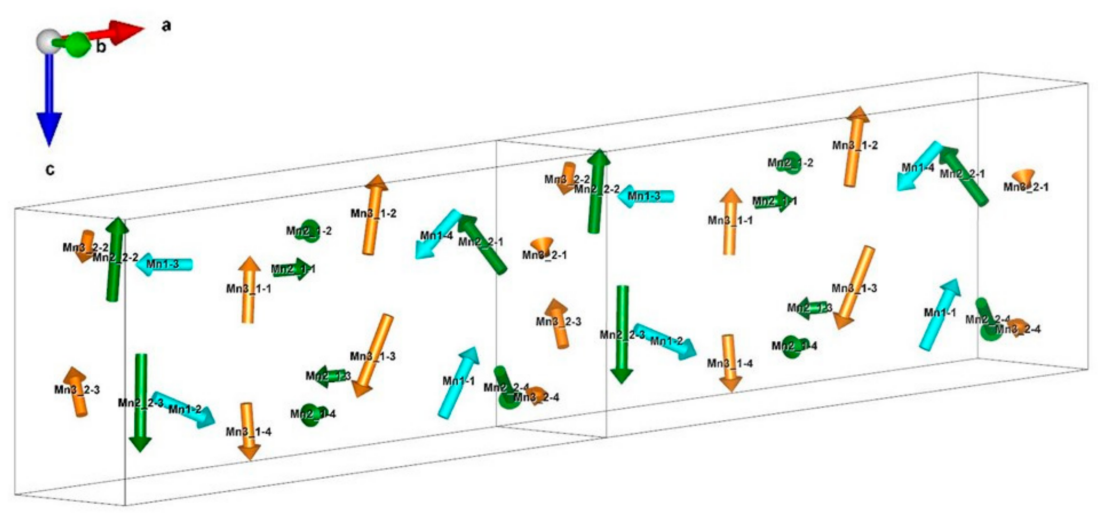

Figure 13. The incommensurately modulated antiferromagnetic spin order in Mn-hureaulite at $1.5 \mathrm{~K}$ (MSSG P2 $1 /$ c. $1^{\prime}(\alpha 0 \gamma) 00$ s with $\boldsymbol{k}(0.523(2), 0,0.055(1))$. 
On the other hand, with $1.5 \mathrm{~K}$ HRNPD data collected with a short wavelength, $\lambda=1.49 \AA$, it was impossible to refine the atomic structure with the magnetic modulations simultaneously because of a serious overlap of main and satellite reflections. This led to the so-called continuum problem. Nonetheless, this study could deliver the incommensurable modulation vector $k(0.523(2), 0,0.055(1))$ for the AMF phase at $1.5 \mathrm{~K}$, which is the first finding for hureaulite-type solid solution compounds. The current model in the incommensurate MSSG P2 ${ }_{1} / \mathrm{c} .1^{\prime}(\alpha 0 \gamma) 00$ s (Figure 13) agrees with observations in neutron powder diffraction more than with a commensurate AFM model with a propagation vector, $\boldsymbol{k}(0.5,0,0)$ (Supplementary Figure S4). Furthermore, a faint peak at about $0.4 \mathrm{~K}$ in the heat capacity of Mn-hureaulite may be a sign for such a commensurate AFM phase stable at lower temperatures, i.e., below $0.4 \mathrm{~K}$.

For the lost $C$-centering, five crystallographically independent $\mathrm{Mn}$ sites were present in the atomic structure of the AFM phase (Supplementary Table S1e), where magnetic moments at five independent $\mathrm{Mn}$ sites were oriented mainly in the $(\boldsymbol{a}-\boldsymbol{c})$ plane, profoundly in $c$ direction (Table 7). Mn1 remained at its solo unique site below $T_{1}$, but Mn2_1 and Mn2_2 became independent of each other with respect to the site Mn2 in the FM phase, as well as Mn3_1 and Mn3_2 with respect to Mn 3. The maximal magnitude of the magnetic moments at Mn1, Mn2_2, and Mn3_1 was much larger than that at Mn2_1 and Mn3_2. In other words, for different magnitudes of magnetic moments between Mn2_1 and Mn2_2, as well as between Mn3_1 and Mn3_2, the magnetic spin order could be regarded as the main driving force for the low-temperature phase transition at $T_{1}$.

Table 7. Modulation of magnetic moments (Bohr magnetons) in Mn-hureaulite at $1.5 \mathrm{~K}$.

\begin{tabular}{|c|c|c|c|c|c|}
\hline Atomic Site & Wave & along $a$ & along $b$ & along $c$ & $\begin{array}{c}\text { Modulation Range of Magnetic } \\
\text { Moment Magnitudes }\end{array}$ \\
\hline \multirow{2}{*}{ Mn1 } & $\sin$ & $4.1(2)$ & 0 & $5.2(3)$ & \multirow{2}{*}{$3.38-4.36$} \\
\hline & $\cos$ & 0 & 0 & $7.0(3)$ & \\
\hline \multirow{2}{*}{ Mn2_1 } & $\sin$ & $1.9(2)$ & $1.3(3)$ & 0 & \multirow{2}{*}{$1.19-2.24$} \\
\hline & $\cos$ & 0 & 0 & 0 & \\
\hline \multirow{2}{*}{$\mathrm{Mn} 2 \_2$} & $\sin$ & $3.9(2)$ & $3.2(4)$ & $-5.1(3)$ & \multirow{2}{*}{$4.31-5.51$} \\
\hline & $\cos$ & $1.3(3)$ & $2.4(1)$ & $3.5(3)$ & \\
\hline \multirow{2}{*}{ Mn3_1 } & $\sin$ & 0 & 0 & $-3.6(3)$ & \multirow{2}{*}{$3.25-4.96$} \\
\hline & $\cos$ & $2.9(3)$ & $2.2(1)$ & $-2.6(3)$ & \\
\hline \multirow{2}{*}{ Mn3_2 } & $\sin$ & 0 & $3.0(3)$ & $5.7(3)$ & \multirow{2}{*}{$0.02-3.96$} \\
\hline & $\cos$ & 0 & 0 & 0 & \\
\hline
\end{tabular}

Strongly modulated directions and magnitudes of magnetic moments at five independent Mn sites (Figure 13) are accompanied by a symmetry lowering of atomic arrangements from $C 2 / \mathrm{c}$ to $P 2_{1} / \mathrm{c}$. The structural part most sensitive to this phase transition is the HB $(\mathrm{O}-\mathrm{H} \cdots \mathrm{O})$ geometry (Figure 14). As given in Table 8, the configuration of each HB pair symmetrically equivalent above $T_{1}$ strongly differs below $T_{1}$. Furthermore, the onset of proton tunneling is expected for the presence of short $\mathrm{HB}$ distance $(\mathrm{d}(\mathrm{O}-\mathrm{H} \cdots \mathrm{O})<2.5 \AA)$ and almost linear $\mathrm{HB}$ bonding angle $\left(\angle(\mathrm{O}-\mathrm{H} \cdots \mathrm{O}) \approx 180^{\circ}\right)$ [6], e.g., d $\left(\mathrm{O} 1 \_2-\mathrm{D} 1 \_2 \cdots \mathrm{O} 8 \_1\right)=$ 2.49(3) $\AA ; \angle\left(O 1 \_2-D 1 \_2 \cdots O 8 \_1\right)=174.2^{\circ}$. 


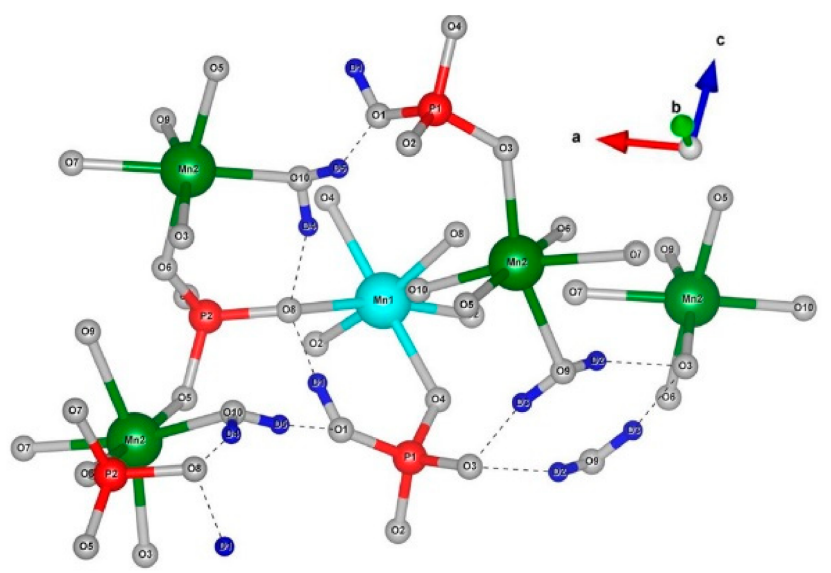

Figure 14. A part of the atomic structure of Mn-hureaulite resulted from Rietveld analyses with HRNPD data at $3.4 \mathrm{~K}$ to show all oxygen and deuterium atoms involved in HBs (dot lines in black) of the title compound.

Table 8. Geometric parameters of $\mathrm{HBs}$ in the PM at $6.5 \mathrm{~K}$, the $\mathrm{FM}$ at $4.5 \mathrm{~K}$, and the AFM phase at $1.5 \mathrm{~K}^{\circ} \mathrm{Mn}^{2+}{ }_{5}$ $\left[\left(\mathrm{PO}_{4}\right)_{2}\left(\mathrm{PO}_{3} \mathrm{OD}\right)_{2}\right](\mathrm{DOD})_{4}$. Two short HBs showing near linear acceptor $(\mathrm{A})-\mathrm{H} \cdots$ donor $(\mathrm{D})$ configurations are highlighted with an asterisk $\left(^{*}\right)$.

\begin{tabular}{|c|c|c|c|c|c|c|c|}
\hline $\mathrm{T}(\mathrm{K})$ & $\begin{array}{l}\text { Donor } \\
\text { (D) }\end{array}$ & $\begin{array}{c}\text { Deuterium/ } \\
\text { Hydrogen (H) }\end{array}$ & $\begin{array}{l}\text { Acceptor } \\
\text { (A) }\end{array}$ & $\begin{array}{c}\text { D-H Distance } \\
\text { (̊̊) }\end{array}$ & 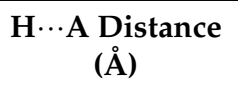 & $\begin{array}{c}\text { D-A Distance } \\
\text { (Å) }\end{array}$ & $\begin{array}{c}\text { A-H } \cdots \text { D Angle } \\
\left({ }^{\circ}\right)\end{array}$ \\
\hline \multirow{5}{*}{6.5} & O1 & D1 & O8 & $1.035(8)$ & $1.637(8)$ & $2.669(8)$ & $174.2(7)$ \\
\hline & O9 & D2 & $\mathrm{O} 3$ & $0.933(9)$ & $1.912(9)$ & 2.807 (9) & $160.1(7)$ \\
\hline & O9 & D3 & O3 & $0.965(9)$ & $1.683(9)$ & $2.638(9)$ & $169.6(7)$ \\
\hline & O10 & D4 & O8 & $0.956(10)$ & $1.750(9)$ & $2.683(9)$ & $164.3(7)$ \\
\hline & O10 & D5 & O1 & $0.962(10)$ & $1.828(9)$ & $2.753(10)$ & $160.6(7)$ \\
\hline \multirow{5}{*}{4.5} & O1 & D1 & O8 & $1.031(5)$ & $1.573(5)$ & $2.601(6)$ & $174.4(4)$ \\
\hline & O9 & D2 & $\mathrm{O} 3$ & $0.979(6)$ & $1.905(6)$ & $2.819(7)$ & $154.3(4)$ \\
\hline & O9 & D3 & $\mathrm{O} 3$ & $0.983(7)$ & $1.678(6)$ & $2.647(7)$ & $167.9(5)$ \\
\hline & O10 & D4 & O8 & $1.001(7)$ & $1.740(6)$ & $2.712(6)$ & $162.7(5)$ \\
\hline & O10 & D5 & O1 & $0.973(7)$ & $1.822(6)$ & $2.710(7)$ & $150.4(5)$ \\
\hline \multirow{10}{*}{1.5} & O1_1 & D1_1 & O8_2 & 1.09 (3) & $1.56(2)$ & $2.63(3)$ & $168(3)$ \\
\hline & O1_2 & D1_2 & O8_1 & $1.01(3)$ & $1.48(3)$ & $2.49(3) *$ & $174(2)$ \\
\hline & O9_1 & D2_1 & O3_1 & 0.99 (3) & 1.69 (3) & 2.67 (3) & $167(2)$ \\
\hline & O9_2 & D2_2 & O3_2 & $1.04(3)$ & $1.61(3)$ & $2.62(4)$ & $162(2)$ \\
\hline & O9_1 & D3_1 & O3_1 & $1.15(3)$ & $1.60(3)$ & $2.71(3)$ & $158.2(2)$ \\
\hline & O9_2 & D3_2 & O3_2 & $0.82(3)$ & $2.12(3)$ & $2.88(3)$ & $154(2)$ \\
\hline & O10_1 & D4_1 & O1_2 & $0.93(3)$ & 1.94 (3) & $2.81(4)$ & $155(2)$ \\
\hline & O10_2 & D4_2 & O1_1 & 0.99 (3) & $1.66(3)$ & $2.52(3)$ & $142(2)$ \\
\hline & O10_1 & D5_1 & O8_1 & $1.11(3)$ & 1.49 (3) & $2.58(3) *$ & $164(2)$ \\
\hline & O10_2 & D5_2 & O8_2 & $0.94(3)$ & $2.15(3)$ & $3.07(4)$ & $166(2)$ \\
\hline
\end{tabular}

For the coexistence of strong variation in magnetic modulations at five Mn sublattices with high geometrical distortion in the HB network, the magnetic spin system seems to strongly interplay with structural dissymmetrization in Mn-hureaulite. These observations presume a high complexity of interplaying structural and magnetic order. In this sense, it is desired to use single-crystal diffraction data to be collected best with polarized neutron or 
synchrotron X-ray sources. This will improve the current new AFM model, but also reveal subtle spin-lattice correlation, eventually driving the phase transition(s) at or below $T_{1}$.

There was no clear indication of a first-order transition for the FM transition at $T_{C}=6.17 \mathrm{~K}$ and the incommensurate AFM transition at $T_{1}=1.86 \mathrm{~K}$. However, when considering the shapes of the $C_{p}$ peaks, the transition at $T_{1}$ was more symmetric, but that at $T_{C}$ was more 'step-like', indicating a first-order and a second-order transition, respectively. A clear step was consistently observed in the entropy change for $T_{1}$, while a soft kink appeared at $T_{C}$ (Figure $4 \mathrm{c}$ ). On the other hand, when the sample was warmed and cooled through a first-order transition, this affected the temperature response $C_{p}$ curve, which no longer had an exponential temperature dependence, and the fitting procedure gave a larger error which could be monitored through the normalized $\chi^{2}$ and/or the estimated heat capacity error. An increased error obtained for the data around the $T_{1}$ transition (Figure $3 b$ ) could be an indication of the first-order type. In contrary, a good exponential fit was obtained in the heating and cooling curves $C_{p}(T)$ around $T_{C}$, which is typical for a second-order transition (i.e., the sample of Mn-hureaulite was heated while continuously following an exponential law through the transition). Hence, the critical point $T_{C}$ may be associated with the second-order transition, accompanying no abrupt jump in the magnetic entropy $S_{m}(\mathrm{~T})$ curve (Figure $4 \mathrm{c}$ ). On the other hand, the existence of a relatively large latent heat at $T_{C}, Q_{L}\left(T_{C}\right)=57 \mathrm{~J} \cdot \mathrm{mol}^{-1}$ necessary for the PM $\rightarrow$ FM transition implies that the transition at $T_{C}$ features a weak first order in nature [23]. In conclusion, the current study cannot give a decisive statement of phase transition types. To accurately determine the order of phase transitions in Mn-hureaulite, further criterial parameters need to be investigated, such as the order of field-dependence of magnetic entropy change and adiabatic temperature change [24].

\section{Conclusions}

This study is the first to successfully provide new magnetic structure models of Mnhureaulite. Its ferrimagnetic phase (MSG: $C 2^{\prime} / c^{\prime}$ ) is stable in a small temperature range of 1.86-6.17 K, showing a continuous change of spin-canting orientations. AFM interactions are dominant for both intra and inter pentamers of $\mathrm{Mn}^{2+}(\mathrm{O}, \mathrm{HOH})_{6}$ octahedra in a spincanted ferrimagnetism of the title compound. In the incommensurate AFM phase (MSSG: $P 2_{1} /$ c. $1^{\prime}(\alpha 0 \gamma) 00$ s) present below $1.86 \mathrm{~K}$, overall magnetic moments vigorously vary along with distinctive distortion of the HB network. The propagation vector $\boldsymbol{k}(0.523(2), 0,0.055(1))$ at $1.5 \mathrm{~K}$ could be determined by Rietveld analyses with HRNPD data. A faint peak at about $0.4 \mathrm{~K}$ in the heat capacity of Mn-hureaulite adumbrates the presence of the basic commensurate AFM phase possibly with $k(0.5,0,0)$ below $0.4 \mathrm{~K}$.

Mn-hureaulite exhibits an interesting spin-canting configuration similar to crossmagnetic sublattices in $\mathrm{LiNiPO}_{4}$, for which field-induced phases show a weak ferromagnetism with strong magnetoelectric effects [25]. Considering the results from the present study, it is worth further investigating the hureaulite-type solid solution compounds under various external fields as possible candidates for application-relevant correlated systems.

Supplementary Materials: The following are available online at https: / www.mdpi.com/article/ $10.3390 /$ sym13091688/s1. We provide all atomic parameters from HRNPD data analyses carried out in this study (Table S1a-e), graphical representations of Rietveld refinements with HRNPD data sets at $4.5 \mathrm{~K}$ (Figure S2a) and $6.1 \mathrm{~K}$ (Figure S2b), temperature-dependent lattice metrics and density (Figure S3), and graphical representation of Rietveld refinements with HRNPD data $1.5 \mathrm{~K}$ (Figure S4a) for a commensurate AFM model (Figure S4b). These are available online.

Author Contributions: Conceptualization, methodology and formal analysis, S.P.; neutron powder diffraction data collection, D.S., M.H., A.H. and S.P.; heat capacity data acquisition and evaluation, A.A.; sample preparation, A.H.; writing-S.P.; writing-review and editing, S.P., A.A. and A.H.; visualization, S.P. and A.A. All authors have read and agreed to the published version of the manuscript. 
Funding: This work was supported by a grant from the Swiss National Supercomputing Centre (CSCS) under project ID s951 and by PSI's share at CSCS with the project ID psi01. A.H. was funded by an Erasmus+ scholarship in the framework of MaMaSELF, provided by the EACEA.

Institutional Review Board Statement: Not applicable.

Informed Consent Statement: Not applicable.

Data Availability Statement: Data supporting reported results can be provided by the corresponding author S.P. upon request.

Acknowledgments: For supporting magnetic measurements, S.P. warmly thanks Christian Pfleiderer and his group at Department of Physics at Technical University München, Garching, Germany.

Conflicts of Interest: The authors declare no conflict of interest.

\section{References}

1. Kohn, M.J.; Rakovan, J.; Hughes, J.M. Phosphates- Geochemical, geobiological, and materials importance, Reviews in Mineralogy \& Geochemistry. Mineral. Mag. 2002, 67, 823-824.

2. Hawthorne, F.C. Structure and chemistry of phosphate minerals. Miner. Mag. 1998, 62, 141-164. [CrossRef]

3. Hartl, A.; Park, S.-H.; Hoelzel, M.; Paul, N.; Gilles, R. Proton conductivity in a hureaulite-type compound, $\mathrm{Mn}_{5}\left[\left(\mathrm{PO}_{4}\right)_{2}\left(\mathrm{PO}_{3}(\mathrm{OH})\right)_{2}\right]$ $(\mathrm{HOH})_{4}$. J. Solid State Chem. 2019, 277, 290-302. [CrossRef]

4. Hartl, A.; Krack, M.; Lunkenheimer, P.; Schulz, A.; Cheptiakov, D.; Appel, M.; Paulmann, C.; Juranyi, F.; Park, S.-H. Proton motions in hydrogen bonds of the hureaulite-type phosphatic oxyhydroxide Mn5[(PO4)2(PO3(OH))2](HOH)4. J. Chem. Phys. in submission.

5. Winkler, M.; Lunkenheimer, P.; Loidl, A.; Park, S.-H.; Röska, B.; Hoelzel, M. Charge transport by global protonic conductivity and relaxational dynamics over hydrogen bonds in $\left(\mathrm{Fe}^{2+} \mathrm{Fe}^{3+}{ }_{3.2}\left(\mathrm{Mn}^{2+}, \mathrm{Zn}\right)_{0.8}\left(\mathrm{PO}_{4}\right)_{3}(\mathrm{OH})_{4.2}(\mathrm{HOH})_{0.8}\right.$. Solid State Ion. 2020, 347, 115240. [CrossRef]

6. Röska, B.; Park, S.-H.; Yoshimori, Y.; Kimura, K.; Kimura, T. Anomalous dielectric response of short hydrogen bonds under pressure: The case of $(\mathrm{Mn}, \mathrm{Fe})^{2+} \mathrm{AlPO}_{4}(\mathrm{OH})_{2} \mathrm{H}_{2} \mathrm{O}$. J. Phys. Condens. Matter 2017, 29, 365401. [CrossRef]

7. Röska, B.; Park, S.-H.; Behal, D.; Hess, K.-U.; Günther, A.; Benka, G.; Pfleiderer, C.; Hoelzel, M.; Kimura, T.; Guenther, A. Determination of the hydrogen-bond network and the ferrimagnetic structure of a rockbridgeite-type compound, $\mathrm{Fe}^{2+} \mathrm{Fe}^{3+}{ }_{3.2}\left(\mathrm{Mn}^{2+}, \mathrm{Zn}\right)_{0.8}\left(\mathrm{PO}_{4}\right)_{3}(\mathrm{OH})_{4.2}(\mathrm{HOH})_{0.8}$. J. Phys. Condens. Matter 2018, 30, 235401. [CrossRef]

8. Behal, D.; Röska, B.; Park, S.-H.; Pedersen, B.; Benka, G.; Pfleiderer, C.; Wakabayashi, Y.; Kimura, T. The first study of anti-ferromagnetic eosphorite-childrenite series $\left(\mathrm{Mn}_{1-x} \mathrm{Fe}_{\mathrm{x}}\right) \mathrm{AlPO}_{4}(\mathrm{OH})_{2} \mathrm{H}_{2} \mathrm{O}(\mathrm{x}=0.5)$. J. Magn. Magn. Mater. 2017, 428, 17-27. [CrossRef]

9. Menchetti, S.; Sabelli, C. The crystal structure of hureaulite, $\mathrm{Mn}_{5}\left(\mathrm{HOPO}_{3}\right)_{2}\left(\mathrm{PO}_{4}\right)_{2}\left(\mathrm{H}_{2} \mathrm{O}\right)_{4}$. Acta Crystallogr. Sect. B Struct. Crystallogr. Cryst. Chem. 1973, 29, 2541-2548. [CrossRef]

10. Gatta, G.D.; Redhammer, G.; Vignola, P.; Meven, M.; McIntyre, G. Single-crystal neutron diffraction and Mössbauer spectroscopic study of hureaulite, $(\mathrm{Mn}, \mathrm{Fe})_{5}\left(\mathrm{PO}_{4}\right)_{2}\left(\mathrm{HPO}_{4}\right)_{2}\left(\mathrm{H}_{2} \mathrm{O}\right)_{4}$. Eur. J. Miner. 2016, 28, 93-103. [CrossRef]

11. Moreira, L.F.; Domingues, P.H.; Mattievich, E. Mössbauer studies of the solid solutions of synthetic hureaulite, $\left[\mathrm{Fe}_{\mathrm{x}} \mathrm{Mn}_{5-\mathrm{x}}\right]\left[\mathrm{PO}_{4} \mathrm{H}\right]_{2}$ $\left[\mathrm{PO}_{4}\right]_{2}\left[\mathrm{H}_{2} \mathrm{O}\right]_{4}$. J. Magn. Magn. Mater. 1994, 132, 191-196. [CrossRef]

12. Domingues, P.-H.; Moreira, L.F.; Mattievich, E.; Sarkissian, B. Magnetism in the series $\left[\mathrm{Fe}_{\mathrm{x}} \mathrm{Mn}_{5-\mathrm{x}}\right]\left[\mathrm{PO}_{4} \mathrm{H}_{2}\left[\mathrm{PO}_{4}\right]_{2}\left[\mathrm{H}_{2} \mathrm{O}\right]_{4}\right.$. J. Magn. Magn. Mater. 1997, 167, 87-92. [CrossRef]

13. Larrea, E.S.; Mesa, J.L.; Pizarro, J.L.; Arriortua, M.I.; Rojo, T. Hydrothermal synthesis, thermal, structural, spectroscopic and magnetic studies of the $\left[\mathrm{Fe}_{\mathrm{x}} \mathrm{Mn}_{5-\mathrm{x}}\right]\left[\mathrm{PO}_{4} \mathrm{H}_{2}\left[\mathrm{PO}_{4}\right]_{2}\left[\mathrm{H}_{2} \mathrm{O}\right]_{4}(\mathrm{x}=1.25,2,2.5\right.$ and 3) finite solid solution. J. Solid St. Chem. 2007, 180, 1686-1697. [CrossRef]

14. Hoelzel, M.; Senyshyn, A.; Juenke, N.; Boysen, H.; Schmahl, W.; Fuess, H. High-resolution neutron powder diffractometer SPODI at research reactor FRM II. Nucl. Instrum. Methods Phys. Res. Sect. A Accel. Spectrometers Detect. Assoc. Equip. 2012, 667, 32-37. [CrossRef]

15. Fischer, P.; Frey, G.; Koch, M.; Könnecke, M.; Pomjakushin, V.; Schefer, J.; Thut, R.; Schlumpf, N.; Bürge, R.; Greuter, U.; et al. High-resolution powder diffractometer HRPT for thermal neutrons at SINQ. Phys. B Condens. Matter 2000, 276, 146-147. [CrossRef]

16. Petř́iček, V.; Dušek, M.; Palatinus, L. Crystallographic Computing System JANA2006: General features. Z. Krist. Cryst. Mater. 2014, 229, 345-352. [CrossRef]

17. Momma, K.; Izumi, F. VESTA: A three-dimensional visualization system for electronic and structural analysis. J. Appl. Crystallogr. 2008, 41, 653-658. [CrossRef]

18. Forstat, H.; Love, N.D.; McElearney, J.N.; Butterworth, G.J. Specific Heat of an Ising Linear-Chain Crystal. Phys. Rev. B 1970, 1, 3097-3100. [CrossRef]

19. Litvin, D.B. Magnetic Group Tables: 1-, 2- and 3-Dimensional Magnetic Subperiodic Groups and Magnetic Space Groups; International Union of Crystallography: Chester, UK, 2013. [CrossRef]

20. Goodenough, J.B. Direct Cation-Cation Interactions in Several Oxides. Phys. Rev. 1960, 117, 1442-1451. [CrossRef] 
21. van Smaalen, S. Incommensurate Crystallography, 1st ed.; IUCr Monography on Crystallography No. 21 Oxford Science Pub-lication: Oxford, UK, 2007.

22. Peres-Mato, J.M.; Ribeiro, J.L.; Petricek, V.; Arroyo, M. Magnetic superspace groups and symmetry constraints in incommen-surate magnetic phases. J. Phys. Condens. Mater 2012, 24, 16320.

23. Yang, C.; Tong, P.; Lin, J.C.; Lin, S.; Cui, D.P.; Wang, B.S.; Song, W.H.; Lu, W.J.; Sun, Y.P. Large magnetic entropy change associated with the weakly first-order paramagnetic to ferrimagnetic transition in antiperovskite manganese nitride CuNMn3. J. Appl. Phys. 2014, 116, 033902. [CrossRef]

24. Law, J.Y.; Franco, V.; Moreno-Ramírez, L.-M.; Conde, A.; Karpenkov, D.Y.; Radulov, I.; Skokov, K.P.; Gutfleisch, O. A quan-titative criterio for determining the order of magnetic phase transitions using the magnetocaloric effect. Nat. Commun. 2018, 9, 2680. [CrossRef] [PubMed]

25. Jensen, T.B.S.; Christensen, N.B.; Kenzelmann, M.; Rønnow, H.M.; Niedermayer, C.; Andersen, N.H.; Lefmann, K.; Schefer, J.; Zimmermann, M.; Li, J.; et al. Field-induced magnetic phases and electric polarization in LiNiPO . Phys. Rev. B 2009, 79, 092412. [CrossRef] 